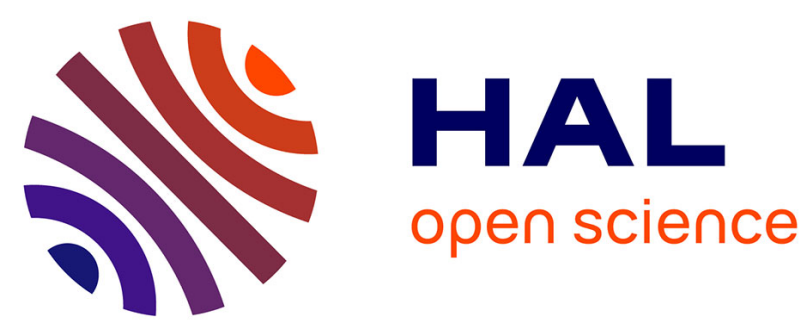

\title{
Total Internal Partition Sums for the HITRAN2020 database
}

Robert R Gamache, Bastien Vispoel, Michaël Rey, Andrei Nikitin, Vladimir

Tyuterev, Oleg Egorov, Iouli E Gordon, Vincent Boudon, Vispoel B Bastien

\section{To cite this version:}

Robert R Gamache, Bastien Vispoel, Michaël Rey, Andrei Nikitin, Vladimir Tyuterev, et al.. Total Internal Partition Sums for the HITRAN2020 database. Journal of Quantitative Spectroscopy and Radiative Transfer, 2021, 271, pp.107713. 10.1016/j.jqsrt.2021.107713 . hal-03406185

\section{HAL Id: hal-03406185 \\ https://hal.science/hal-03406185}

Submitted on 27 Oct 2021

HAL is a multi-disciplinary open access archive for the deposit and dissemination of scientific research documents, whether they are published or not. The documents may come from teaching and research institutions in France or abroad, or from public or private research centers.
L'archive ouverte pluridisciplinaire HAL, est destinée au dépôt et à la diffusion de documents scientifiques de niveau recherche, publiés ou non, émanant des établissements d'enseignement et de recherche français ou étrangers, des laboratoires publics ou privés. 
Total Internal Partition Sums for the HITRAN2020 database

Robert R. Gamache ${ }^{\mathrm{a},}$, Bastien Vispoel ${ }^{\mathrm{b} . c}$, Michaël Rey ${ }^{\mathrm{d}}$, Andrei Nikitin ${ }^{\mathrm{e}}$, Vladimir Tyuterev ${ }^{\mathrm{d}, \mathrm{f}}$, Oleg Egorov, Iouli E. Gordon ${ }^{\mathrm{g}}$, Vincent Boudon ${ }^{\mathrm{h}}$

${ }^{a}$ Department of Environmental, Earth, and Atmospheric Sciences University of Massachusetts

Lowell, Lowell, MA 01854 USA

${ }^{\mathrm{b}}$ Research Unit Lasers and Spectroscopies (LLS), Institute of Life, Earth and Environment (ILEE), University of Namur (UNamur), 61 rue de Bruxelles, B-5000, Namur, Belgium

${ }^{\mathrm{c}}$ Royal Belgian Institute for Space Aeronomy (BIRA-IASB), 3 Avenue Circulaire, 1180 Brussels, Belgium

${ }^{\mathrm{d}}$ Groupe de Spectrométrie Moléculaire et Atmosphérique, UMR CNRS 7331, Université de Reims, U.F.R. Sciences, B.P. 1039, 51687 Reims Cedex 2, France

e Laboratory of Theoretical Spectroscopy, V.E. Zuev Institute of Atmospheric Optics, SB RAS 1, Akademician Zuev Sq., Tomsk 634055, Russian Federation

${ }^{\mathrm{f}}$ Laboratory of Quantum Mechanics of Molecules and Radiative Processes, Tomsk State University, 36, Lenin Ave., Tomsk 634050, Russian Federation

${ }^{\mathrm{g}}$ Harvard-Smithsonian Center for Astrophysics, Atomic and Molecular Physics Division, Cambridge, MA 02138 USA

${ }^{\mathrm{h}}$ Laboratoire Interdisciplinaire Carnot de Bourgogne, UMR 6303 CNRS, Université Bourgogne Franche-Comté, 9 Av A. Savary, BP 47870, F-21078 Dijon Cedex, France

‡Corresponding author: Robert Gamache, Robert_Gamache@uml.edu 


\begin{abstract}
Total internal partition sums (TIPS) are reported for the 181 isotopologues of 57 molecules important in planetary atmospheres. Molecules 1 to 55, with the exception of \#34 atomic oxygen, are taken from the HITRAN2020 list, and for some molecules additional isotopologues are considered. Molecules 56 and 57 are $\mathrm{C}_{3} \mathrm{H}_{4}, \mathrm{CH}_{3}$, respectively. New to TIPS are the calculations for ${ }^{12} \mathrm{CH}_{4},{ }^{13} \mathrm{CH}_{4},{ }^{12} \mathrm{CH}_{3} \mathrm{D},{ }^{13} \mathrm{CH}_{3} \mathrm{D},{ }^{14} \mathrm{~N}^{16} \mathrm{O},{ }^{15} \mathrm{~N}^{16} \mathrm{O},{ }^{14} \mathrm{~N}^{18} \mathrm{O},{ }^{16} \mathrm{O}^{32} \mathrm{~S}^{18} \mathrm{O}$, ${ }^{33} \mathrm{~S}^{16} \mathrm{O}_{2},{ }^{15} \mathrm{~N}^{16} \mathrm{O}_{2},{ }^{18} \mathrm{OH},{ }^{16} \mathrm{OD},{ }^{35} \mathrm{Cl}^{16} \mathrm{O},{ }^{37} \mathrm{Cl}^{16} \mathrm{O},{ }^{16} \mathrm{O}^{13} \mathrm{C}^{34} \mathrm{~S},{ }^{32} \mathrm{~S}^{19} \mathrm{~F}_{6},{ }^{12} \mathrm{C}_{2} \mathrm{H}_{5} \mathrm{D},{ }^{12} \mathrm{C}_{2} \mathrm{H}_{3} \mathrm{D},{ }^{12} \mathrm{C}^{19} \mathrm{~F}_{4}$, ${ }^{12} \mathrm{CH}_{3}{ }^{19} \mathrm{~F},{ }^{70} \mathrm{GeH}_{4},{ }^{72} \mathrm{GeH}_{4},{ }^{73} \mathrm{GeH}_{4},{ }^{74} \mathrm{GeH}_{4},{ }^{76} \mathrm{GeH}_{4},{ }^{12} \mathrm{CH}_{3}{ }^{127} \mathrm{I}^{13} \mathrm{CH}_{3}{ }^{127} \mathrm{I}$, and ${ }^{14} \mathrm{~N}^{19} \mathrm{~F}_{3}$. In addition, all the molecules/isotopologues that were not recalculated for TIPS2017 (Gamache et al., JQSRT 203, 70, 2017) have been recalculated using the 2014 CODATA physical constants. The TIPS are determined by various methods from 1 to $5000 \mathrm{~K}$. These data are provided with HITRAN2020 and a new version of the TIPS code is available in both FORTRAN and python languages.
\end{abstract}

Keywords: Total Internal Partition Sum (TIPS); molecules/isotopologues on HITRAN2020; TIPS_2021_v1p0.for; TIPS_2021_v1p0.py. 


\section{INTRODUCTION}

The Total Internal Partition Sums (TIPS) are a very useful quantity in chemistry and physics. The equation of state of a gas, the thermodynamic functions (internal energy, enthalpy, entropy, Helmholtz free energy, and Gibbs free energy), heat capacity, etc. can be written in terms of the TIPS and its dependence on temperature [1]. Given a number density of molecules, the TIPS can be used to determine the population of molecules as a function of quantum state. These population factors are needed to determine the intensity of ro-vibrational transitions. The expressions that show the relationships between the intensity of a spectral line and the square of the transition moment, the Einstein- $A$ coefficient, or the oscillator strength [2] all contain the partition sum.

When applying radiative-transfer (RT) models to study planetary atmospheres, there is a set of input parameters needed for the models, which includes the line position, lower-state energy, intensity at a reference temperature, the line shape parameters for the atmospheric pressure regimes. These parameters can be found in molecular spectroscopic databases such as HITRAN [3, 4] or GEISA [5]. Because planetary atmospheres are not isothermal, the temperature dependence of these parameters must be known. The temperature dependence of both line shape parameters, the half-width and the line shift, was derived by Gamache and Vispoel [6]. While HITRAN has adopted the Gamache and Vispoel model, most of the data for the half-widths are the old power law form, $\gamma(T)=\gamma\left(T_{r e f}\right)\left[\frac{T_{r e f}}{T}\right]^{n}$ and few data are presented for the line shift. For the line intensity, S, for a transition $f \leftarrow i$ the dependence on temperature is given by 


$$
S_{f \leftarrow i}(T)=S_{f \leftarrow i}\left(T_{r e f}\right) \frac{Q\left(T_{r e f}\right)}{Q(T)} \frac{e^{-h c E " / k T}}{e^{-h c E " / k T_{r e f}}} \frac{\left[1-e^{-h c \omega_{f \leftarrow i} / k T}\right]}{\left[1-e^{-h c \omega_{f \leftarrow i} / k T_{r e f}}\right]}
$$

Where $Q(T)$ is the total internal partition sum, $h$ and $\underline{k}$ are the Planck and Boltzmann constants, $c$ is the speed of light, $h c E$ " is the lower state energy, i.e. $E_{i}$, and $\omega_{f \in i}$ is the wavenumber of the transition. Thus, these expressions allow the parameters on HITRAN or GEISA to be propagated to other temperatures.

For high temperature applications such as stellar atmospheres, Sauval and Tatum [7] calculated partition functions for roughly 300 diatomic molecules over a temperature range of 1000 to $9000 \mathrm{~K}$. Irwin [8] refined the work of Sauval and Tatum for $\mathrm{H}_{2}$ and $\mathrm{CO}$ and later [9] calculated partition functions for polyatomic molecules that significantly affect the stellar atmospheric equation of state and which were of interest to the JANAF (Joint-Army-Navy-Air Force) program [10]. In 2016, Barklem and Collet [11] determined partition functions and dissociation equilibrium constants for 291 diatomic molecules for temperatures in the range from near absolute zero to $10000 \mathrm{~K}$.

This work is an update and an extension of previous studies [12-19] that calculated TIPS for the molecules and isotopologues present on the HITRAN databases [3, 4, 20-25] and for astrophysical applications. In 1990 Gamache et al. [12] presented TIPS for the 11 closed shell linear molecules and their isotopologues in HITRAN86 [20]. The Q(T) data were given by polynomial expansions in two temperature ranges: $70-400$ and 400-2005 K and a logarithmic expansion that allowed extrapolation to $3000 \mathrm{~K}$. This work was extended [13] to include all molecular/isotopologue species on HITRAN92 [21] and three additional molecular/isotopologue species from HITRAN96 [22]. The Q(T) data were made for temperatures from 70 to $3005 \mathrm{~K}$. 
The data were divided into three temperature regions and each region fit by a $3^{\text {rd }}$ order polynomial. In 2002, Fischer and Gamache made TIPS calculations for 5 molecules (16 isotopologues) abundant in Planetary atmospheres [15]. They also made partition sum calculations for Non-Local Thermodynamic Equilibrium (NLTE) applications [16]. Using the same temperature ranges as the previous study [15], they used $4^{\text {th }}$ order polynomials to fit the data. Fischer et al. [17] calculated TIPS for the 40 molecules and 95 isotopologues/isotopomers present on the HITRAN2000 database [23]. They also added an additional 13 lesser abundant isotopologues/isotopomers of ozone and carbon dioxide. The calculations were done from 703000K, however, now the data were recalled using a Lagrange 4-point interpolation scheme. In 2011, Laraia et al. [18] determined TIPS for 14 molecules (33 isotopologues) needed to support planetary remote sensing. The molecules of this study are now part of HITRAN2020. Finally, in 2017 new calculations were made for 24 molecules (73 isotopologues) in the HITRAN2016 database [19]. All of the calculations represented an improvement over previous calculations, many using ab initio energy levels to do direct summations of Q(T). In fact, in all of the above studies the methods of calculating $Q(T)$ were improved upon from earlier studies.

There are many other examples of high-quality partition sums in the literature, i.e. partition sums that use accurate energy values and are converged at the temperatures reported. Some recent examples include work on $\mathrm{MgH}$ by Szidarovszky and Császár [26], on $\mathrm{H}_{2}{ }^{16} \mathrm{O}$ by Furtenbacher et al. [27], and on three isotopologues of $\mathrm{D}_{2} \mathrm{O}$ by Simkó et al. [28].

It should be noted that when one scans the literature, the terms partition function and partition sum are often interchanged. Here, the standard chemistry notation, $Q(T)$, is adopted for the total internal partition sum as a function of temperature $T$. The total partition function is assumed to be the product of the internal and the translational partition functions. 
In this work, the total internal partition sums are calculated for a number of molecules and isotopologues new to the HITRAN database and some improvements to previous calculations, they are: ${ }^{12} \mathrm{CH}_{4},{ }^{13} \mathrm{CH}_{4},{ }^{12} \mathrm{CH}_{3} \mathrm{D},{ }^{13} \mathrm{CH}_{3} \mathrm{D},{ }^{14} \mathrm{~N}^{16} \mathrm{O},{ }^{15} \mathrm{~N}^{16} \mathrm{O}$, and ${ }^{14} \mathrm{~N}^{18} \mathrm{O},{ }^{16} \mathrm{O}^{32} \mathrm{~S}^{18} \mathrm{O}$, ${ }^{33} \mathrm{~S}^{16} \mathrm{O}_{2},{ }^{15} \mathrm{~N}^{16} \mathrm{O}_{2},{ }^{18} \mathrm{OH},{ }^{16} \mathrm{OD},{ }^{35} \mathrm{Cl}^{16} \mathrm{O},{ }^{37} \mathrm{Cl}^{16} \mathrm{O},{ }^{16} \mathrm{O}^{13} \mathrm{C}^{34} \mathrm{~S},{ }^{32} \mathrm{~S}^{19} \mathrm{~F}_{6},{ }^{12} \mathrm{C}_{2} \mathrm{H}_{5} \mathrm{D},{ }^{12} \mathrm{C}_{2} \mathrm{H}_{3} \mathrm{D},{ }^{12} \mathrm{C}^{19} \mathrm{~F}_{4}$ ${ }^{12} \mathrm{CH}_{3}{ }^{19} \mathrm{~F},{ }^{70} \mathrm{GeH}_{4},{ }^{72} \mathrm{GeH}_{4},{ }^{73} \mathrm{GeH}_{4},{ }^{74} \mathrm{GeH}_{4},{ }^{76} \mathrm{GeH}_{4},{ }^{12} \mathrm{CH}_{3}{ }^{127} \mathrm{I},{ }^{13} \mathrm{CH}_{3}{ }^{127} \mathrm{I}$, and ${ }^{14} \mathrm{~N}^{19} \mathrm{~F}_{3}$. These new calculations used the 2014 Codata values of the fundamental physical constants [29]. However, the data for a number of the molecules/isotopologues on the 2017 version of TIPS came from previous work $[13,18]$ that used older values of the physical constants. The TIPS have been recalculated for all of these molecules/isotopologues using the 2014 Codata values to provide consistent values for all molecules/isotopologues. In the new calculations the maximum temperature was set to $5000 \mathrm{~K}$ and the calculations made in $1 \mathrm{~K}$ steps starting at $1 \mathrm{~K}$. In this work, the calculations of the TIPS do not consider unbound states. Recall of the data is possible using either a FORTRAN stand-alone program (TIPS_2021_v1p0.for), a blockdata subroutine code (BD_TIPS_2021_v1p0.for), or a Python code (TIPS_2021_v1p0.py).

Section 2 describes the calculation of total internal partition sums and is primarily intended for those new to these calculations. These methods have been presented in previous publications [15-19] so only a quick overview is presented with appropriate references given. Section 3 describes the methods used to calculate $\mathrm{Q}(\mathrm{T})$ for each molecule/isotopologue of this work. The codes to quickly recall the $\mathrm{Q}(\mathrm{T})$ values are presented in section 4 and, finally, section 5 summarizes the work.

\section{DETERMINING THE TOTAL INTERNAL PARTITION SUM}


Every isotopologue of a molecule has a unique set of quantum energy states, $F_{s .}$ The total internal partition sum is given by summing the factor $e^{-h c F_{s} / k T}$ over all states $s$ of the isotopologue. Here $h c F_{S}$ is the total energy (electronic, vibrational, rotational, and any other quantized motion) of state $s . F_{s}$ is the term value [30] and has units of $\mathrm{cm}^{-1}$. When energy states are degenerate, the sum need only be done once multiplied by the degeneracy factor, of which some are state dependent; i.e. it depends on the quantum numbers of the state, $d_{s}$, or state independent; i.e. it is a factor given for the molecule, $d_{i}$. Given these factors, $Q(T)$, can be written as

$$
Q_{\text {elec, } \text {, vib,rot,tors, etc. }}(T)=d_{i} d_{\text {allstatess }} d^{-h c F_{s} / k T}
$$

The $d_{s}$ factors are generally composed of two components. The first is the rotational and total angular momentum degeneracy factor and is given in terms of the quantum numbers: $(2 J+l)$ or $(2 F+1)$. When molecules have symmetry such that identical atoms can be interchanged by a symmetry operation, e.g. $\mathrm{CH}_{4}$ or $\mathrm{H}_{2} \mathrm{O}$, only certain products of rotational and nuclear wavefunctions yield the proper symmetry for the complete wavefunctions. For such cases, even and odd symmetry states have different nuclear spin weight and these values must be factored into Eq. (2) accordingly. The calculation of these nuclear statistical weights depends on whether the nuclei being exchanged have half-integer spins (Fermi systems) or integer spins (Bose systems). For details see Refs. [19] or [30]. Some examples include; for $\mathrm{H}_{2} \mathrm{O}$, the two hydrogen atoms that are interchanged have spin $1 / 2$ nuclei giving a three-fold degeneracy for the odd states and a onefold degeneracy for the even states; for $\mathrm{C}^{16} \mathrm{O}_{2}$, the two oxygen atoms that are exchanged have spin zero nuclei giving one-fold degeneracy for the even levels and a zero-fold degeneracy for the odd levels (i.e., such levels do not exist). 
In this work, the state independent factors are explicitly included in the determination of $Q(T)$. However, in the literature, state independent factors are often omitted from partition sum calculations when the application involves a ratio of partition sums. Note, these factors are necessary to relate the partition functions to thermodynamic quantities. The state independent degeneracy factor is given by the product $\Pi(2 I+1)$, where $I$ is the nuclear spin and the product is taken over all nuclei not interchanged by rotations [30]. Thus, when comparing the partition sums from this study to values from the literature, it is sometimes necessary to multiply by an integer value to obtain agreement due to the omission of the state independent factors.

The method of evaluation of $Q(T)$ depends on the availability of the energy levels and corresponding degeneracy factors for the molecule/isotopologue in question. The ideal situation is to have energy levels up to the dissociation limit of the isotopologue in question. For such cases, a direct sum using Eq. (2) can be done. However, seldom are energy levels available up to the dissociation limit. The question then becomes, given the set of energy levels available, to what temperature can $Q(T)$ accurately be computed. Since, as the energy increases, the exponential factor approaches zero and the sum can be truncated with no loss of accuracy. The work done on TIPS2017 took advantage of the many ab initio determinations of ro-vibrational energy levels that allowed direct sums over Eq. (2) to be done. However, there are many molecules/isotopologues for which a full set of energy levels are not available. In addition, there are often additional structures, such as lambda doubling, torsional motion, etc. for which the energy expressions are more complicated. For all cases, the energy is assumed to be additive

$$
E(\text { elec }, \text { vib }, \text { rot }, \text { tors }, \ldots)=E_{\text {elec }}+E_{\text {vib }}+E_{\text {rot }}+E_{\text {tors }}+\ldots
$$

Taking advantage of the property of the exponential, Eq. (2) can be rewritten

$$
Q(\text { elec }, \text { vib }, \text { rot }, \text { tors }, \ldots)=Q_{\text {elec }} \leftrightarrow Q_{v i b} \leftrightarrow Q_{\text {rot }} \leftrightarrow Q_{\text {tors }} \leftrightarrow \ldots
$$


which is called the product approximation, PA. Often, $Q_{\text {elec }}$ is equal to one and there is no torsional structure. For such a case the product approximation gives

$$
Q(T)=Q_{v i b} \leftrightarrow Q_{r o t}=g_{i=0}^{i_{\max }} g_{v_{i}} e^{-h c \omega_{J} / k T} \leftrightarrow{ }_{J=0}^{J_{\max }} g_{J} e^{-h c E_{J} / k T}
$$

However, when the molecule under consideration is a linear Bose system caution must be made when applying the product approximation. Consider ${ }^{12} \mathrm{C}^{16} \mathrm{O}_{2}$ as an example. The vibrational states are labeled by $v_{1} v_{2} \quad \ell_{2} v_{3}$ and when $\ell_{2}=0$ only even $J$ levels are allowed (Bose statistics for nuclei with spin equal zero being exchanged). When $\ell_{2}>0$ all $J$ levels are allowed. The sum over states can be rewritten as

$$
Q(T)=\left(\sum_{\substack{\text { all vibstates } \\
\text { with } \ell_{2}=0}} g e^{-E_{v} / k T}\right)\left(\sum_{\begin{array}{c}
J=0 \\
\text { even only }
\end{array}}^{J_{\max }} g_{J} e^{-E_{r} / k T}\right)+\left(\sum_{\substack{\text { allvibstates } \\
\text { with } \ell_{2}>0}} g e^{-E_{v} / k T}\right)\left(\sum_{\substack{J=0 \\
\text { even\& odd }}}^{J_{\max }} g_{J} e^{-E_{r} / k T}\right)
$$

Or equivalently

$$
Q(T)=Q_{v i b}^{\ell_{2}=0}(T) \leftarrow Q_{\text {rot }}(\text { J even })+Q_{\text {vib }}^{\ell_{2}>0}(T) \leftarrow \bigcup_{\text {rot }}(\text { all } J)
$$

which can be called the double product approximation, DPA.

For ${ }^{12} \mathrm{C}^{16} \mathrm{O}_{2}$ sufficient ab initio term values exist to converge the TIPS to $5000 \mathrm{~K}$, thus allowing a comparison between the PA and the DPA. Figure 1 shows the TIPS determined by direct summation of Eq. (2) (red dashed-line), the TIPS determined by the double product approximation blue (solid line with + symbols), Eq. (6), and the TIPS determined by the product approximation (black dot-dashed line), Eq. (5) versus temperature. The PA underestimates the TIPS by $\sim 50 \%$ at high temperatures, but even at low temperatures the differences grow quickly: $\sim 1 \%$ at $200 \mathrm{~K}, 4 \%$ at $300 \mathrm{~K}, 13 \%$ at $500 \mathrm{~K}$.

Insert Figure 1 Here 
When it is not possible to do a direct sum over energies, Eq. (4) reduces the problem to computing the electronic, vibrational, rotational, ... partition sums. There are various approximations that can be used to compute each. Generally, $Q_{\text {elec }}$ is one, however, for a number of molecules sums over electronic states must be done, such as $\mathrm{NO}$ or $\mathrm{O}_{2}$. For $Q_{v i b}$ the harmonic oscillator approximation (HOA) of Herzberg is often used [30] or the inclusion of anharmonic corrections [19]. There are a number of analytical representations for $Q_{\text {rot }}$ [31-34] that are given in terms of the rotational constants. See Ref. [19] for the expressions of these quantities.

\section{CALCULATIONS}

Table 1 lists for the molecules/isotopologues shown below the molecule number, isotopologue number, the original HITRAN isotopologue code, $Q(296 \mathrm{~K})$, and maximum temperature of the calculation. For molecule/isotopologues that have not changed from TIPS_2017, a short description of the method of calculations is presented, complete details can be found in the original paper [19].

\subsection{Water Vapor}

The $Q(T)$ values for the nine isotopologues of $\mathrm{H}_{2} \mathrm{O}$ shown in Table 1 are from Ref. [19]. For all isotopologues, the method of calculation was direct sums over ab initio term values, which were calculated to high $J$ values to ensure convergence of the partition sums at all temperatures. 


\subsection{Carbon Dioxide}

The $Q(T)$ values for the thirteen isotopologues of $\mathrm{CO}_{2}$ shown in Table 1 are from Ref. [19]. The calculations were made by direct summation using the ab initio energy levels form the work of Huang et al. [35-37] and are converged for all reported temperatures.

\subsection{Ozone}

In a quest towards the sub-percent uncertainty of the intensities of ozone lines across multiple spectral regions, the quality of the partition sums becomes particularly important. In a recent study by Birk et al. [38] it was found that the partition sums of the ${ }^{16} \mathrm{O}_{3}$ isotopologue at 296K differ from those in the JPL catalogue [39] and S\&MPO database [40] by about 0.3\%. The partition some in S\&MPO are considered to be most accurate as they are obtained through direct summation of the most complete set of ab initio energy levels. The computation of partition sums for ozone is problematic due to a number of factors: a) a low dissociation threshold, $\mathrm{D}_{0}$; b) important contributions of metastable levels above $\mathrm{D}_{0}$ which depend on their lifetime; $\mathrm{c}$ ) severe convergence issues for high T; d) three potential wells due to Jahn-Teller effect, which implies singularities in rotational constants at linear configurations when nuclear are vibrating among these wells; and e) the inclusion of bound state vib-rot levels of excited electronic states with spin effects for the triplet states. Because of these issues, the partition sums are limited here to a maximum temperature of $1000 \mathrm{~K}$.

For the principal isotopologue, ${ }^{16} \mathrm{O}_{3}$, the TIPS values have been determined by a direct summation [41] using a combination of experimental rovibrational levels for low and medium energies [42] and global variational calculations [43] accounting for dense patterns of levels near the dissociation threshold [44] using ab initio potential energy surface of Tyuterev et al. [45]. 
The details of the direct sum calculations will be reported elsewhere [41]. For the other17 isotopologues of ozone shown in Table 1, total internal partition sums were recalculated using the 2014 Codata constants. The $Q_{v i b}$ values were determined using the harmonic oscillator approximation [30] and the $Q_{\text {rot }}$ values were determined using the analytical expression of Watson [34] with the latest vibrational and rotational constants from the S\&MPO database [40]. Calculations were made from 1-1000 K.

\subsection{Nitrous Oxide}

The $Q(T)$ values for the ${ }^{14} \mathrm{~N}_{2}{ }^{16} \mathrm{O}$ isotopologue is from Ref. [19], which was a direct sum using the data of Tashkun et al. [46]. Those for the ${ }^{14} \mathrm{~N}^{15} \mathrm{~N}^{16} \mathrm{O},{ }^{15} \mathrm{~N}^{14} \mathrm{~N}^{16} \mathrm{O},{ }^{14} \mathrm{~N}_{2}{ }^{18} \mathrm{O}$, and ${ }^{14} \mathrm{~N}_{2}{ }^{17} \mathrm{O}$ isotopologues were recalculated using the 2014 Codata constants and the vibrational and rotational constants of Toth [47]. The HOA was used to calculate $Q_{v i b}$ and McDowell formula for linear molecules [31] was used for $Q_{r o t}$.

\subsection{Carbon Monoxide}

The $Q(T)$ values for the nine isotopologues of CO shown in Table 1 are from Ref. [19]. The partition sum calculations were made by direct summation over the energy levels of Li et al. [48], which includes all levels to $v=41$ and $J=150$. The $Q(T)$ data were reported to $9000 \mathrm{~K}$.

\subsection{Methane}

Total internal partition sums are reported for the ${ }^{12} \mathrm{CH}_{4},{ }^{13} \mathrm{CH}_{4},{ }^{12} \mathrm{CH}_{3} \mathrm{D}$, and ${ }^{13} \mathrm{CH}_{3} \mathrm{D}$ isotopologues of methane. The data for all isotopologues were calculated using the 2014 Codata 
constants and the calculations were made from 1-2500 K. The calculations of TIPS included both direct sums over ab initio term values and the product approximation as described below.

Because of the structure of the vibrational states of methane and its isotopologues, the classical vibrational partition sum only provides reasonable results at low temperatures. For example, considering $Q_{v i b}$ for ${ }^{12} \mathrm{CH}_{4}$ at $296 \mathrm{~K}$, the difference between a direct sum and the classical harmonic oscillator approximation is $\sim 0.1 \%$, however by $700 \mathrm{~K}$, the difference is $\sim 7 \%$ and it increases to $\sim 75 \%$ at $2500 \mathrm{~K}$. Therefore, calculations were made for the $G\left(v_{1}, v_{2}, v_{3}, v_{4}\right)$ values $(J=0)$ for ${ }^{12} \mathrm{CH}_{4}$ and ${ }^{13} \mathrm{CH}_{4}$ and $G\left(v_{1}, v_{2}, v_{3}, v_{4}, v_{5}, v_{6}\right)$ for ${ }^{12} \mathrm{CH}_{3} \mathrm{D}$ and ${ }^{13} \mathrm{CH}_{3} \mathrm{D}$. For these molecules the normal mode representation is a good choice providing an adequate description of the nuclear motions. The normal mode kinetic energy operator was built in the frame of the Eckart-Watson (EW) formalism [49]. The curvilinear potential energy surface (PES) reported by Nikitin et al. [50] was transformed and Taylor-expanded in mass-dependent normal mode coordinates $\mathrm{Q}$ adapted to the $\mathrm{T}_{\mathrm{d}}$ and $\mathrm{C}_{3 \mathrm{v}}$ point groups. Both the kinetic and potential parts have been expanded at order 14 in Q and reduced at order 7 using the technique described by Rey et al. [51]. To account for symmetry, the use of the irreducible tensor operator technique was used to build the EW Hamiltonian and ro-vibrational basis functions following Refs. [52, 53] while energy levels were computed by variational method.

The $\mathrm{J}=0$ vibrational problem was first solved using a direct product of harmonic oscillator functions where a "pruned" vibrational basis was considered by selecting a limited number of functions through the criterion

$$
F(n)={ }_{i=1}^{M} k_{i} v_{i} \leq n
$$

with $M=4$ for $T_{d}$ species and $M=6$ for $C_{3 V}$ species. Here, $v_{i}=0, \ldots, n$ and $k_{i}$ are weighting coefficients. For this work, $n=16$ and $k_{\mathrm{i}}=\{1.1 ; 1 ; 1.1 ; 1\}$ for ${ }^{12} \mathrm{CH}_{4}$ and ${ }^{13} \mathrm{CH}_{4}$ and $n=14$ and $k_{\mathrm{i}}=$ 
$\{1.2 ; 1.1 ; 1 ; 1.2 ; 1 ; 1\}$ for ${ }^{12} \mathrm{CH}_{3} \mathrm{D}$ and ${ }^{13} \mathrm{CH}_{3} \mathrm{D}$, resulting in 52062, 47028, 99041, 145354 and 150382 functions for the symmetry blocks $\{$ A1, A2, E, F1, F2 $\}$ and 70552, 65855 and 136374 functions for the symmetry blocks $\{\mathrm{A} 1, \mathrm{~A} 2, \mathrm{E}\}$, respectively. The use of such basis sets represents an improvement of previous results $[53,54]$. Contrary to the effective polyad models, variational calculations require the diagonalization of very large matrices for $\mathrm{J}>0$, even for computing pure rotational energy levels. To this end, a set of vibrational reduced eigenfunctions obtained from the projection technique [51] was introduced to drastically reduce dimensionality of the full problem, making thus calculations feasible even for high J values. From this analysis $G\left(v_{1}, v_{2}, v_{3}, v_{4}\right)$ for ${ }^{12} \mathrm{CH}_{4}$ and ${ }^{13} \mathrm{CH}_{4}$ and $G\left(v_{1}, v_{2}, v_{3}, v_{4}, v_{5}, v_{6}\right)$ for ${ }^{12} \mathrm{CH}_{3} \mathrm{D}$ and ${ }^{13} \mathrm{CH}_{3} \mathrm{D}$ were determined with a cutoff in vibrational energy at 134 152, 121261,68871 , and $121260 \mathrm{~cm}^{-1}$, respectively. These vibrational energies were used to determine $Q_{v i b}(T)$ for the four isotopologues of methane.

For the principal isotopologue, ${ }^{12} \mathrm{CH}_{4}, Q(T)$ was first determined by direct sum over $a b$ initio term values, which were calculated for levels up to $J=67$ and are complete to $\sim 15,000 \mathrm{~cm}^{-1}$. These partition sums are converged to $\sim 1300 \mathrm{~K}$. Next, the rotational term values for ${ }^{12} \mathrm{CH}_{4}$ were calculated for states with $J=0$ to 80 from an effective Hamiltonian calculation of the ground vibrational state. These term values are complete to $30,424 \mathrm{~cm}^{-1}$ and were used to compute the direct sum for $Q_{r o t}$, which are converged at all temperatures. The $Q_{v i b}$ values were determined by a direct sum over $G_{v}$ values as described above. The final $Q(T)$ data for ${ }^{12} \mathrm{CH}_{4}$ are the direct sum values up to $1300 \mathrm{~K}$ and the product approximation values from 1301 to $2500 \mathrm{~K}$.

Because the term values for ${ }^{13} \mathrm{CH}_{4}$ are almost identical to those for ${ }^{12} \mathrm{CH}_{4}$, the TIPS for ${ }^{13} \mathrm{CH}_{4}$ were determined by multiplying the ${ }^{12} \mathrm{CH}_{4}$ TIPS by 2 to account for the spin of ${ }^{13} \mathrm{C}$. These values were compared to the product approximation $Q(T)$, where $Q_{r o t}$ was determined using the 
rotational constants of Dang-Nhu et al. [55] in McDowell's analytical formula [33] and $Q_{v i b}$ as determined above, and the results are identical at high T. Note that the corresponding TIPS are in a much better agreement with the temperature dependence of $Q(T)$ obtained by Nikitin et al. [56] using the PES of [52] and the contact transformation method [57] compared to other $Q(T)$ values available in the literature. The comparison with Nikitin et al. [56] shows $0.01 \%$ difference at $300 \mathrm{~K}$ and $0.02 \%$ difference at $1000 \mathrm{~K}$.

For the two deuterated isotopologues, the analytical formula of McDowell [32] was used to compute $Q_{r o t}$ with the rotational constants of Tarrago et al. [58] for ${ }^{12} \mathrm{CH}_{3} \mathrm{D}$ and those of Ulenikov et al. [59] for ${ }^{13} \mathrm{CH}_{3} \mathrm{D}$. The final $Q(T)$ for the two deuterated isotopologues were determined via the product approximation, $Q_{r o t}($ analytical $) * Q_{v i b}($ direct sum $)$.

\subsection{Oxygen molecule}

The $Q(T)$ values for the six isotopologues of $\mathrm{O}_{2}$ shown in Table 1 are from Ref. [19]. The calculations were made by direct summation over a set of term values complete to $\sim 39000$ $\mathrm{cm}^{-1}[60]$ for all isotopologues. The TIPS converge to $7500 \mathrm{~K}$ for all isotopologues.

\subsection{Nitric Oxide}

The TIPS for ${ }^{14} \mathrm{~N}^{16} \mathrm{O},{ }^{15} \mathrm{~N}^{16} \mathrm{O}$, and ${ }^{14} \mathrm{~N}^{18} \mathrm{O}$ were calculated via the product approximation using the 2014 Codata constants. Rotational term values were taken from an update to the HITEMP database [61] and are from the work of Hargraves et al. [62]. The term values were determined up to $J=184.5, F=185.5 ; J=99.5, F=100.5$; and $J=99.5, F=100.5$ and are complete to 51423,15747 , and $15747 \mathrm{~cm}^{-1}$, respectively. These term values were used to compute $Q_{\text {rot }}$ by 
direct sum. The vibrational term values are $1876.0765 \mathrm{~cm}^{-1}, 1843.02092 \mathrm{~cm}^{-1}$, and 1827.38716 $\mathrm{cm}^{-1}$, respectively, and were used to compute $Q_{v i b}$ via the HOA. The calculations were made from 1 to $5000 \mathrm{~K}$ and are converged at all temperatures.

\subsection{Sulfur Dioxide}

The TIPS for ${ }^{32} \mathrm{~S}^{16} \mathrm{O}_{2}$ and ${ }^{34} \mathrm{~S}^{16} \mathrm{O}_{2}$ were recalculated by the product approximation using the 2014 Codata constants. $Q_{\text {rot }}$ was computed using Watson's analytical model with rotational constants from Pine [63] and $Q_{v i b}$ used the vibrational term values of Lafferty et al. [64] in the harmonic oscillator approximation. Two new isotopologues were considered; ${ }^{16} \mathrm{O}^{32} \mathrm{~S}^{18} \mathrm{O}$ and ${ }^{33} \mathrm{~S}^{16} \mathrm{O}_{2}$. For ${ }^{16} \mathrm{O}^{32} \mathrm{~S}^{18} \mathrm{O}$ the rotational constants and the $v_{1}$ and $v_{3}$ vibrational energies are from Ulenikov et al. [65]. The $v_{2}$ vibrational energy was scaled from the ${ }^{32} \mathrm{~S}^{16} \mathrm{O}_{2}$ value using the average ratio of the $v_{1}$ and $v_{3}$ vibrational energies: e.g. $v_{1}\left({ }^{16} \mathrm{O}^{32} \mathrm{~S}^{18} \mathrm{O}\right) / \mathrm{v}_{1}\left({ }^{32} \mathrm{~S}^{16} \mathrm{O}_{2}\right)$. The rotational constants and the $v_{2}$ vibrational energy are from Blake et al. [66]. The $v_{1}$ and $v_{3}$ vibrational energies were scaled from the ${ }^{32} \mathrm{~S}^{16} \mathrm{O}_{2}$ values using the ratio $v_{2}\left({ }^{33} \mathrm{~S}^{16} \mathrm{O}_{2}\right) / v_{2}\left({ }^{32} \mathrm{~S}^{16} \mathrm{O}_{2}\right)$. The calculations were made from $1-5000 \mathrm{~K}$.

\subsection{Nitrogen Dioxide}

The TIPS for ${ }^{14} \mathrm{~N}^{16} \mathrm{O}_{2}$ were recalculated via the product approximation using the 2014 Codata constants from $1-1000 \mathrm{~K}$. The rotational constants were taken from Perrin et al. [67] and used in Watson's analytical formula. The vibrational term values are from Norton and Rinsland [68] and were used in Herzberg's HOA.

\subsection{Ammonia}


The $Q(T)$ values for the two isotopologues of $\mathrm{NH}_{3}$ shown in Table 1 are from Ref. [19]. The TIPS were calculated by direct summation over the ab initio energies of Yurchenko et al. $[69,70]$ and are converged to $6000 \mathrm{~K}$.

\subsection{Nitric Acid}

The $Q(T)$ values for the two isotopologues of $\mathrm{HNO}_{3}$ shown in Table 1 are from Ref. [19]. The TIPS were calculated via the product approximation where $Q_{\text {rot }}$ was determined by Watson's analytical formula [34] and $Q_{v i b}$ was determined via the Harmonic oscillator approximation of Herzberg.

\subsection{Hydroxyl radical}

The $Q(T)$ values for the ${ }^{16} \mathrm{OH}$ isotopologues of $\mathrm{OH}$ shown in Table 1 are from Ref. [19]. These were determined from a direct summation over the term values of Brooke et al. [71] and are converged to $9000 \mathrm{~K}$. For the ${ }^{18} \mathrm{OH}$ and ${ }^{16} \mathrm{OD}$ isotopologues, the rotational term values for the ${ }^{2} \prod_{1 / 2},{ }^{2} \prod_{3 / 2}$, and ${ }^{2} \Sigma_{1 / 2}$, states were calculated using the formalism of Beaudet and Poynter [72] which includes the fine structure interaction and lambda doubling. This procedure generated energies complete to $42000 \mathrm{~cm}^{-1}$ for ${ }^{18} \mathrm{OH}$, and $39000 \mathrm{~cm}^{-1}$ for ${ }^{16} \mathrm{OD}$. Rotational and vibrational partition sums were calculated using the 2014 Codata constants from 1-5000 K. The total internal partition sums were determined by the product approximation. Figure 2 shows $Q_{\text {rot }}$ for ${ }^{18} \mathrm{OH}$ versus the term value in $\mathrm{cm}^{-1}$ at $\mathrm{T}=500,1000,2000,3000,4000$, and $5000 \mathrm{~K}$ demonstration convergence. The saw tooth structure at low term value is due to the structure of the energy; groups of 4 near identical term values for the ${ }^{2} \prod_{3 / 2} \pm$ states for the states with $F=$ $J \pm 0$. The data for the ${ }^{16} \mathrm{OD}$ isotopologue shows similar convergence. 
Insert Fig 2 here

\subsection{Hydrogen Fluoride}

The $Q(T)$ values for $\mathrm{H}^{19} \mathrm{~F}$ and $\mathrm{D}^{19} \mathrm{~F}$ are from Ref. [19]. The TIPS were determined by direct summation over the term values of Li et al. [73] giving results that are converged to 6000 $\mathrm{K}$.

\subsection{Hydrogen Chloride}

The $Q(T)$ values for $\mathrm{H}^{35} \mathrm{Cl}, \mathrm{H}^{37} \mathrm{Cl}, \mathrm{D}^{35} \mathrm{Cl}$, and $\mathrm{D}^{37} \mathrm{Cl}$ are from Ref. [19]. The TIPS for these isotopologues of $\mathrm{HCl}$ were determined by direct summation over the term values of $\mathrm{Li}$ et al. [73] giving results that are converged to $6000 \mathrm{~K}$.

\subsection{Hydrogen Bromide}

The $Q(T)$ values for the four isotopologues of $\mathrm{HBr}$ shown in Table 1 are from Ref. [19]. They were also determined by direct summation over the term values of Li et al. [73] giving results that are converged to $6000 \mathrm{~K}$.

\subsection{Hydrogen Iodide}


The $Q(T)$ values for $\mathrm{H}^{127} \mathrm{I}$ and $\mathrm{D}^{127} \mathrm{I}$ are from Ref. [19]. The last of the hydrogen halides, HI, the TIPS were also determined by direct summation over the term values of Li et al. [73] giving results that are converged to $6000 \mathrm{~K}$.

\subsection{Chlorine Monoxide}

The TIPS reported for ${ }^{35} \mathrm{Cl}^{16} \mathrm{O}$ and ${ }^{37} \mathrm{Cl}^{16} \mathrm{O}$ were determined via the product approximation. The ground vibrational state term values for $\mathrm{ClO}$, an inverted doublet in Hund's case (a), were computed for the ${ }^{2} \prod_{1 / 2}$ and ${ }^{2} \prod_{3 / 2}$ states using the formalism of Endo et al. [74] with the constants of Cohen et al. [75]. Term value calculations were made to $J=249.5$ (F=251) and are complete to 33800 and $33323 \mathrm{~cm}^{-1}$ for ${ }^{35} \mathrm{Cl}^{16} \mathrm{O}$ and ${ }^{37} \mathrm{Cl}^{16} \mathrm{O}$, respectively. These term values were used to compute $Q_{\text {rot }}$ by direct summation. $Q_{\text {vib }}$ were computed with $v_{1}=841.6 \mathrm{~cm}^{-1}$ $\left({ }^{35} \mathrm{Cl}^{16} \mathrm{O}\right)$ and $v_{1}=837.2 \mathrm{~cm}^{-1}\left({ }^{37} \mathrm{Cl}^{16} \mathrm{O}\right)$. The $Q(T)$ values were determined from $1-5000 \mathrm{~K}$. Note, all partition sums were determined using the 2014 Codata constants. Figure 3 shows $Q_{\text {rot }}$ for ${ }^{35} \mathrm{Cl}^{16} \mathrm{O}$ versus the term value in $\mathrm{cm}^{-1}$ for the temperatures $500,1000,2000,3000,4000$, and $5000 \mathrm{~K}$. The last 900 term values of a sorted list of 3990 values only change Q(5000 K) by 0.33 $\%$ demonstrating rotational partition sums are converged.

Insert Fig 3 here

\subsection{Carbonyl Sulfide}

Previous editions of HITRAN had five isotopologues of carbonyl sulfide: ${ }^{16} \mathrm{O}^{12} \mathrm{C}^{32} \mathrm{~S}$, ${ }^{16} \mathrm{O}^{12} \mathrm{C}^{34} \mathrm{~S},{ }^{16} \mathrm{O}^{13} \mathrm{C}^{32} \mathrm{~S},{ }^{16} \mathrm{O}^{12} \mathrm{C}^{33} \mathrm{~S}$, and ${ }^{18} \mathrm{O}^{12} \mathrm{C}^{32} \mathrm{~S}$. HITRAN2020 has data for the ${ }^{16} \mathrm{O}^{13} \mathrm{C}^{34} \mathrm{~S}$ 
isotopologue. All isotopologues were calculated by the product approximation with the 2014 Codata constants at temperatures from 1-5000 K. The rotational constants for the first five isotopologues are from Maki [76] and those for ${ }^{16} \mathrm{O}^{13} \mathrm{C}^{34} \mathrm{~S}$ are from Burenin et al. [77]. The vibrational constants are from Refs. [68, 78, 79].

\subsection{Formaldehyde}

Three isotopologues of formaldehyde were considered in this work: $\mathrm{H}_{2}{ }^{12} \mathrm{C}^{16} \mathrm{O}, \mathrm{H}_{2}{ }^{13} \mathrm{C}^{16} \mathrm{O}$, and $\mathrm{H}_{2}{ }^{12} \mathrm{C}^{18} \mathrm{O}$. The calculations of $Q_{v i b}$ and $Q_{\text {rot }}$ were done from 1-5000 K using the 2014 Codata constants. The rotational constants are from Winnewisser et al. [80] and the vibrational fundamentals are from Norton and Rinsland [68]. The product approximation was used to determine the total internal partition sum.

\subsection{Hypochlorous acid}

The total internal partition sums for $\mathrm{H}^{16} \mathrm{O}^{35} \mathrm{Cl}$ and $\mathrm{H}^{16} \mathrm{O}^{37} \mathrm{Cl}$ were calculated using the product approximation. The $Q_{\text {rot }}$ values were recalculated using the rotational constants of Lovas [81]. The calculation of $Q_{v i b}$ used the vibrational frequencies of Norton and Rinsland [68]. The partition sum calculations used the 2014 Codata constants and are reported from 1-5000 K.

\subsection{Nitrogen molecule}

The $Q(T)$ values for the three isotopologues of nitrogen shown in Table 1 are from Ref. [19]. The partition sums were calculated by direct summation over a rather complete set of term values from the work of Le Roy et al. [82], giving values converged to $9000 \mathrm{~K}$. 


\subsection{Hydrogen Cyanide}

The $Q(T)$ values for the three isotopologues of hydrogen cyanide, $\mathrm{H}^{12} \mathrm{C}^{14} \mathrm{~N}, \mathrm{H}^{13} \mathrm{C}^{14} \mathrm{~N}$, and $\mathrm{H}^{12} \mathrm{C}^{15} \mathrm{~N}$ are from Ref. [19]. The TIPS were determined by a combination of direct summation over the ab initio term values of Harris et al. $[83,84]$ from $1-1000 \mathrm{~K}$ and via the product approximation from 1001-3500 K, where $Q_{v i b}$ was determined by direct summation and $Q_{\text {rot }}$ was determined using the analytical formula of McDowell [31].

3.24 Methyl Chloride (IUPAC name: chloromethane)

The total internal partition sums for the ${ }^{12} \mathrm{CH}_{3}{ }^{35} \mathrm{Cl}$ and ${ }^{12} \mathrm{CH}_{3}{ }^{37} \mathrm{Cl}$ isotopologues of methyl chloride were recalculated using the 2014 Codata constants. The TIPS were determined from 1$5000 \mathrm{~K}$ via the product approximation. The $Q_{\text {rot }}$ values were determined using the constants of Di Lauro and Alamichel [85] in the analytical expression of McDowell [32]. The $Q_{v i b}$ values were determined by the HOA using the vibrational frequencies of Norton and Rinsland [68].

\subsection{Hydrogen Peroxide}

The $Q(T)$ values for the $\mathrm{H}_{2}{ }^{16} \mathrm{O}_{2}$ isotopologue shown in Table 1 are from Ref. [19]. The TIPS were determined by direct summation over the ab initio term values of Al-Refaie et al. [86] allowing convergence to $6000 \mathrm{~K}$.

\subsection{Acetylene}

The $Q(T)$ values for the ${ }^{12} \mathrm{C}_{2} \mathrm{H}_{2}$ isotopologue are from Ref. [19], which was a direct summation using the term values of Amyay et al. [87]. For the $\mathrm{H}^{12} \mathrm{C}^{13} \mathrm{CH}$ and $\mathrm{H}^{12} \mathrm{C}^{12} \mathrm{CD}$ isotopologues the TIPS were recalculated via the product approximation. The calculation of $Q_{r o t}$ 
used the rotational constants from Refs. [88] and [89] and the $Q_{v i b}$ HOA calculations used the vibrational frequencies from NIST tables (http://webbook.nist.gov) and Ref. [89] for $\mathrm{H}^{12} \mathrm{C}^{13} \mathrm{CH}$ and $\mathrm{H}^{12} \mathrm{C}^{12} \mathrm{CD}$, respectively. The calculations were done from 1-5000 $\mathrm{K}$ using the 2014 Codata constants.

\subsection{Ethane}

The TIPS for ${ }^{12} \mathrm{C}_{2} \mathrm{H}_{6}$ and ${ }^{12} \mathrm{CH}_{3}{ }^{13} \mathrm{CH}_{3}$ were recalculated via the product approximation using the 2014 Codata constants. Qrot values were computed using McDowell's analytical formula [32] and the rotational constants of Duncan et al. [90]. Qvib was computed using the HOA and the vibrational frequencies of Norton and Rinsland [68]. The TIPS were determined for a new isotopologue, ${ }^{12} \mathrm{C}_{2} \mathrm{H}_{5} \mathrm{D}$, using the rotational constants of Daly et al. [91] in Watson's analytical formula. Q $\mathrm{vib}_{\text {vib }}$ values were determined with the $v_{1}, v_{2}, v_{3}, v_{4}, v_{12}, v_{13}, v_{14}$ vibrational fundamentals from Doney et al. [92]; the $v_{5}, v_{6}, v_{7}, v_{8}, v_{10}, v_{15}$ vibrational fundamentals from Kondo and Saeki [93]; and the $v_{9}, v_{11}, v_{16}, v_{17}, v_{18}$ from Daly et al. [91]. Daly et al. report the partition sums at a few temperatures from 9.375 to $300 \mathrm{~K}$. In their calculations they only consider the tortional degeneracy, $g_{t}=4$. The calculations made here also include the stateindependent degeneracy factor: $\left(2 \mathrm{I}_{\mathrm{H}}+1\right)^{2 *}\left(2 \mathrm{I}_{12} \mathrm{C}+1\right)^{2 *}\left(2 \mathrm{I}_{\mathrm{D}}+1\right)=12$. Thus, taking ratios of our computed Q(T) values to those of Daly et al. give a ratio of 12 . The final TIPS go from 1-5000 $\mathrm{K}$.

\subsection{Phosphine}


The $Q(T)$ values for phosphine, ${ }^{31} \mathrm{PH}_{3}$ are from Ref. [19], where a direct summation on term values form the work of Sousa-Silva et al. [94]. The TIPS were converged and reported to $4500 \mathrm{~K}$

\subsection{Carbonyl Fluoride}

The total internal partition sums for the two isotopologues of carbonyl fluoride shown in Table 1 are from Ref. [19]. The TIPS were determined using the product approximation with $Q_{v i b}$ via the HOA and $Q_{r o t}$ via Watson's analytical formula.

\subsection{Sulfur Hexafluoride}

The total internal partition sums for ${ }^{32} \mathrm{~S}^{19} \mathrm{~F}_{6}$ were computed by $Q_{v i b}$ x $Q_{\text {rot }}$, where the rotational partition sum was evaluated by analytical formula [33] using the constants of Faye et al. [95] The vibrational partition sums were computed using the HOA with the following vibrational state frequencies listed in Table 2. All calculations used the 2014 Codata constants and considered temperature from 1 to $5000 \mathrm{~K}$. The $Q(296 \mathrm{~K})$ value determined here agrees has a $0.2 \%$ difference compared with the ab initio determined value of Rey et al. [96].

Table 2. Vibrational normal mode wavenumbers in $\mathrm{cm}^{-1}$ for ${ }^{32} \mathrm{~S}^{19} \mathrm{~F}_{6}$.

\begin{tabular}{|l|c|c|c|}
\hline State & Frequency in $\mathrm{cm}^{-1}$ & Degeneracy & Ref. \\
\hline$v_{1}$ & $774.545540(66)$ & 1 & {$[95]$} \\
\hline$v_{2}$ & $643.373626(43)$ & 2 & {$[95]$} \\
\hline$v_{3}$ & $948.1025121(21)$ & 3 & {$[95]$} \\
\hline$v_{4}$ & $614.98196(15)$ & 3 & {$[97]$} \\
\hline
\end{tabular}




\begin{tabular}{|l|c|c|c|}
\hline$v_{5}$ & $524.027934(93)$ & 3 & {$[98]$} \\
\hline$v_{6}$ & $347.736707(35)$ & 3 & {$[99]$} \\
\hline
\end{tabular}

\subsection{Hydrogen Sulfide}

The $Q(T)$ values for the $\mathrm{H}_{2}{ }^{32} \mathrm{~S}$ isotopologue are from Ref. [19]. The TIPS for the $\mathrm{H}_{2}{ }^{34} \mathrm{~S}$ and $\mathrm{H}_{2}{ }^{33} \mathrm{~S}$ isotopologues were recalculated by the product approximation. The rotational partition sums used the analytical formula of Watson [34] with the constants of Flaud et al. [100]. The $Q_{v i b}$ calculations used the HOA with the constants of Norton and Rinsland [68]. The partition sum calculations were from 1-5000 K and used the 2014 Codata constants.

\subsection{Formic Acid}

The TIPS for $\mathrm{H}^{12} \mathrm{C}^{16} \mathrm{O}^{16} \mathrm{OH}$ were computed via $Q_{v i b}$ x $Q_{r o t}$, where the rotational partition sum was evaluated by analytical formula of Watson [34] with the constants of Willemot [101]. $Q_{v i b}$ values were determined using the HOA with the constants of Norton and Rinsland [68]. Both calculations were done over the range 1-5000 K and used the 2014 Codata constants.

\subsection{Hydroperoxyl radical}

TIPS were recalculated for the $\mathrm{H}^{16} \mathrm{O}_{2}$ isotopologue via the product approximation. $Q_{r o t}$ values were determined via the analytical formula of Watson [34] using the constants of Charo and DeLucia [102]. Because $\mathrm{HO}_{2}$ is an open shell molecule, $Q_{r o t}$ was multiplied by a factor of 2 to account for the F splitting. $Q_{v i b}$ values were determined using the HOA with the constants of Ref. [68]. The calculations were made from 1 to $5000 \mathrm{~K}$ using the 2014 Codata constants. 


\subsection{Oxygen atom}

No data are reported for the oxygen atom.

\subsection{Chlorine Nitrate}

TIPS were computed for two isotopologues of chlorine nitrate: ${ }^{35} \mathrm{Cl}^{16} \mathrm{O}^{14} \mathrm{~N}^{16} \mathrm{O}_{2}$ and ${ }^{37} \mathrm{Cl}^{16} \mathrm{O}^{14} \mathrm{~N}^{16} \mathrm{O}_{2}$. The rotational partition sums used Watson's analytical formula [34] with the constants of Carten and Lovejoy [103]. The $Q_{v i b}$ values come from a HOA calculation using the constants of Norton and Rinsland [68]. Both calculations used the 2014 Codata constants. The final $Q(T)$ values are reported from $1-5000 \mathrm{~K}$.

\subsection{Nitric Oxide cation}

The TIPS for ${ }^{14} \mathrm{~N}^{16} \mathrm{O}^{+}$ion (also known as the nitrosonium ion) were recalculated by the product approximation with rotational and vibrational constants taken from von Esse [104]. $Q_{r o t}$ values were determined using McDowell analytical formula and $Q_{v i b}$ values were from the HOA; both calculations ranged from 1 to $5000 \mathrm{~K}$ and used the 2014 Codata constants.

\subsection{Hypobromous Acid}

The TIPS for two isotopologues of hypobromous acid, $\mathrm{H}^{16} \mathrm{O}^{79} \mathrm{Br}$ and $\mathrm{H}^{16} \mathrm{O}^{81} \mathrm{Br}$, were recalculated using the product approximation. The rotational $Q(T)$ values were determined using Watson analytical formula and the vibrational $Q(T)$ values were determined via the HOA. Both calculations used the molecular constants of Cohen [105], the 2014 Codata constants, and were done for temperatures from 1 to $5000 \mathrm{~K}$. 


\subsection{Ethylene}

The TIPS for ${ }^{12} \mathrm{C}_{2} \mathrm{H}_{4}$ and ${ }^{12} \mathrm{CH}_{2}{ }^{13} \mathrm{CH}_{2}$ were recalculated from 1-5000 K using the 2014 Codata constants. The rotational constants are from Tan et al. [106] and [107], respectively, and used in Watson's analytical formula. The vibrational frequencies are from the work of Georges et al. [108] for ${ }^{12} \mathrm{C}_{2} \mathrm{H}_{4}$, from Duncan et al. [109, 110] for ${ }^{12} \mathrm{CH}_{2}{ }^{13} \mathrm{CH}_{2}$ and were used to calculate $Q_{v i b}$ via the HOA. New to HITRAN is the ${ }^{12} \mathrm{C}_{2} \mathrm{H}_{3} \mathrm{D}$ isotopologue. Watson's formula was used for $Q_{r o t}$ with the constants of Herbin et al. [111] and $Q_{v i b}$ calculated using the HOA with the vibrational constants of Viglaska et al. [112]. The $296 \mathrm{~K}$ partition sums calculated in this work are in a good agreement with the ab initio direct sum results of Rey et al. [113] for ${ }^{12} \mathrm{C}_{2} \mathrm{H}_{4}$, the difference being of $0.4 \%$.

\subsection{Methanol}

The $Q(T)$ values for the ${ }^{12} \mathrm{CH}_{3}{ }^{16} \mathrm{OH}$ isotopologue shown in Table 1 are from Ref. [19]. They were determined via the product approximation where $Q_{v i b}$ was determined using the vibrational energies from the Virtual Planetary Laboratory of the University of Washington [114], which includes the torsional state and the rotational constants of De Lucia et al. [115]in the analytical formula of Watson.

\subsection{Methyl Bromide (IUPAC name: bromomethane)}

TIPS for two isotopologues of methyl bromide, ${ }^{12} \mathrm{CH}_{3}{ }^{79} \mathrm{Br}$ and ${ }^{12} \mathrm{CH}_{3}{ }^{81} \mathrm{Br}$, were recalculated from 1-5000 K using the 2014 Codata constants. The rotational partition sums of both isotopologues were computed using the symmetric-top analytical formula of McDowell 
[32]. The vibrational partition sums were computed using the HOA of Herzberg with the vibrational frequencies from Refs. [116-119].

3.41 Methyl Cyanide (IUPAC name: acetonitrile)

The TIPS for four isotopologues of methyl cyanide were recalculated via the product approximation from 1-5000 K using the 2014 Codata constants: ${ }^{12} \mathrm{CH}_{3}{ }^{12} \mathrm{C}^{14} \mathrm{~N},{ }^{13} \mathrm{CH}_{3}{ }^{12} \mathrm{C}^{14} \mathrm{~N}$, ${ }^{12} \mathrm{CH}_{3}{ }^{13} \mathrm{C}^{14} \mathrm{~N}$, and ${ }^{13} \mathrm{CH}_{3}{ }^{13} \mathrm{C}^{14} \mathrm{~N}$. The rotational constants for the principal isotopologue are from Simeckova et al. [120] and those for the other three isotopologues are from Boucher et al. [121]. These constants were used in McDowell's symmetric-top analytical formula. The vibrational frequencies were taken from Refs. [122-125] and used to compute $Q_{v i b}$ via the HOA.

\subsection{Carbon Tetrafluoride}

While ${ }^{12} \mathrm{C}^{19} \mathrm{~F}_{4}$ has been on the HITRAN database for some time, the TIPS were not reported. Here the TIPS have been calculated via the product approximation from 1-5000 K using the 2014 Codata constants. The rotational and vibrational constants are from Carlos et al. [126]. The rotational partition sums were calculated using McDowell's spherical-top formula and the vibrational partition sums were calculated via Herzberg's HOA. The TIPS value at 296 $\mathrm{K}$ determined in this work agrees well, $0.2 \%$ difference, with the ab initio results of Rey et al. [51].

\subsection{Diacetylene}

The total internal partition sums for the ${ }^{12} \mathrm{C}_{4} \mathrm{H}_{2}$ isotopologue of diacetylene (1,3butadiyne) were recalculated from $1-5000 \mathrm{~K}$ using the 2014 Codata constants. The linear 
molecule analytical formula of McDowell [31] was used with the rotational constants of Arie and Johns [127]. The vibrational partition sums were calculated via Herzberg's HOA using the vibrational frequencies from Refs. [127-133]. The TIPS were formed by $Q_{v i b} \mathrm{x} Q_{\text {rot }}$.

\subsection{Cyanoacetylene}

The TIPS for 6 isotopologues of cyanoacetylene, $\mathrm{H}^{12} \mathrm{C}_{3}{ }^{14} \mathrm{~N}, \mathrm{H}^{12} \mathrm{C}_{3}{ }^{15} \mathrm{~N}, \mathrm{H}^{12} \mathrm{C}^{12} \mathrm{C}^{13} \mathrm{C}^{14} \mathrm{~N}$, $\mathrm{H}^{12} \mathrm{C}^{13} \mathrm{C}^{12} \mathrm{C}^{14} \mathrm{~N}, \mathrm{H}^{13} \mathrm{C}^{12} \mathrm{C}^{12} \mathrm{C}^{14} \mathrm{~N}$, and $\mathrm{D}^{12} \mathrm{C}^{12} \mathrm{C}^{12} \mathrm{C}^{14} \mathrm{~N}$, were recalculated from $1-5000 \mathrm{~K}$ using the 2014 Codata constants. The rotational partition sums used the analytical formula of McDowell [31] with the constants of Lafferty and Lovas [134]. Using the vibrational frequencies from Refs. [130, 135-140] the vibrational partition sums were calculated using the HOA. The TIPS were formed using the product approximation.

\subsection{Hydrogen molecule}

The $Q(T)$ values for $\mathrm{H}_{2}$ and $\mathrm{HD}$ are from Ref. [19] where direct sums were made over the term values of Piszczatowski et al. [141] for $\mathrm{H}_{2}$ and from Pachucki et al. [142] for HD. The TIPS were reported to $6000 \mathrm{~K}$.

\subsection{Carbon Monosulfide}

The TIPS for four isotopologues of carbon monosulfide, ${ }^{12} \mathrm{C}^{32} \mathrm{~S},{ }^{12} \mathrm{C}^{34} \mathrm{~S},{ }^{13} \mathrm{C}^{32} \mathrm{~S}$, and ${ }^{12} \mathrm{C}^{33} \mathrm{~S}$ were recalculated using the product approximation from 1 to $5000 \mathrm{~K}$ using the 2014 Codata constants. The rotational partition sums were computed via McDowell's linear molecule analytical formula using the constants of Burkholder et al. [143]. The vibrational frequencies were also taken from Burkholder et al. to compute the vibrational partition sums. 


\subsection{Sulfur Trioxide}

The $Q(T)$ values for ${ }^{32} \mathrm{~S}^{16} \mathrm{O}_{3}$ are from Ref. [19] where a direct sum was made using the term values from the work of Underwood et al. [144], which converged to $650 \mathrm{~K}$. $Q(T)$ values were also computed via the product approximation using the rotational and vibrational constants of Maki et al. [145]. The final TIPS are from a direct sum from 1-650 K and the product approximation from $651-3500 \mathrm{~K}$.

\subsection{Cyanogen}

The TIPS for two symmetric isotopologues of cyanogen, ${ }^{14} \mathrm{~N}^{12} \mathrm{C}^{12} \mathrm{C}^{14} \mathrm{~N}$ and ${ }^{15} \mathrm{~N}^{12} \mathrm{C}^{12} \mathrm{C}^{15} \mathrm{~N}$, were recalculated from $1-5000 \mathrm{~K}$ by the product approximation using the 2014 Codata constants. The $Q_{\text {rot }}$ values were computed using McDowell's linear molecule analytical formula with the constants of Maki [146]. The vibrational partition sums were computed via the HOA using the frequencies from Grecu et al. [147].

\subsection{Phosgene}

The $Q(T)$ values for the ${ }^{12} \mathrm{C}^{16} \mathrm{O}^{35} \mathrm{Cl}_{2}$ and ${ }^{12} \mathrm{C}^{16} \mathrm{O}^{35} \mathrm{Cl}^{37} \mathrm{Cl}$ isotopologues of phosgene are from Ref. [19]. The TIPS were determined from 1-5000 K via the product approximation using the rotational constants of Tchana et al. [148] and the vibrational energies for $v_{1}$ and $v_{5}$ from Tchana et al. [148] and $v_{2}, v_{3}$, and $v_{4}$ from the NIST webbook (http://webbook.nist.gov).

\subsection{Sulfur Monoxide}


Sulfur Monoxide is a new HITRAN molecule, which was assigned number \#50 to be consistent with TIPDS_2017 which already contained this molecule. The TIPS for three isotopologues of sulfur monoxide, ${ }^{32} \mathrm{~S}^{16} \mathrm{O},{ }^{34} \mathrm{~S}^{16} \mathrm{O}$, and ${ }^{32} \mathrm{~S}^{18} \mathrm{O}$, were recalculated from 1-5000 $\mathrm{K}$ using the 2014 Codata constants. There is no analytical formula for this $X^{3} \Sigma$ molecule so direct sums of $Q_{\text {rot }}$ were determined for each isotopologue. Term values were computed for $J$ up to 250 using the constants of Burkholder et al. [143] giving Term values to more than $52000 \mathrm{~cm}^{-1}$ for each isotopologue, ensuring convergence of the rotational partition sums at all temperatures of the study. The vibrational frequencies are also from of Burkholder et al. and were used in the HOA to compute $Q_{v i b}$. The final $Q(T)$ values were determined by $Q_{v i b} \mathrm{x} Q_{r o t}$.

\subsection{Methyl Fluoride (IUPAC name Fluoromethane)}

Methyl fluoride is a new species on the HITRAN database, molecule \#51. The TIPS for the ${ }^{12} \mathrm{CH}_{3}{ }^{19} \mathrm{~F}$ isotopologue were determined from 1-5000 $\mathrm{K}$ using the product approximation with the 2014 Codata constants. The rotational constants of Papousek et al. [149] were used to determine the rotational partition sums with McDowell's symmetric-top analytical formula. The vibrational partition sums were computed via the HOA with the constants from the NIST Chemistry Webbook (webbook.nist.gov/chemistry/).

\subsection{Germane}

Germane is a new species on the HITRAN database, molecule \#52. The TIPS were determined from 1-5000 K using the product approximation with the 2014 Codata constants for five isotopologues: ${ }^{70} \mathrm{GeH}_{4},{ }^{72} \mathrm{GeH}_{4},{ }^{73} \mathrm{GeH}_{4},{ }^{74} \mathrm{GeH}_{4},{ }^{76} \mathrm{GeH}_{4}$. The rotational partition sums were calculated using the spherical-top formula of McDowell [33] and the constants of Richard et al. 
[150]. The vibrational partition sums were calculated via the HOA with the vibrational fundamentals from Refs. $[150,151]$. The TIPS for ${ }^{74} \mathrm{GeH}_{4}$ are consistent with the direct sum $a b$ initio results reported by Nikitin et al. [152] with very small differences of $0.004 \%$ and $0.08 \%$ at 80 and $298 \mathrm{~K}$.

\subsection{Carbon Disulfide}

Carbon disulfide is a new species on the HITRAN database, molecule \#53; however, it was included in TIPS_2017. Note, the symmetric species are Bose particles, so the double product approximation must be used to compute $Q(T)$ analytically. The double product approximation was not used in TIPS_2017, so there are large differences with the TIPS computed here for the symmetric species. Those presented in this work should be used. The TIPS were determined with the 2014 Codata constants from 1-5000 K using the double product approximation for ${ }^{12} \mathrm{C}^{32} \mathrm{~S}_{2},{ }^{13} \mathrm{C}^{32} \mathrm{~S}_{2}$, and the product approximation for ${ }^{32} \mathrm{~S}^{12} \mathrm{C}^{34} \mathrm{~S}_{2}$, and ${ }^{32} \mathrm{~S}^{12} \mathrm{C}^{33} \mathrm{~S}_{2}$. The rotational constants for all four isotopologues are from Karlovets et al. [153] and were used to compute the partition sums via McDowell's linear molecule analytical formula. The $\mathrm{G}_{\mathrm{v}}$ values are also from Karlovets et al. [153] for the four isotopologues. Note however, the $G_{v}\left(01^{1} 0\right)$ value for ${ }^{32} S^{12} C^{33} S_{2}$ was estimated from the average ratio $G_{v}\left(02^{0} 0\right) / G_{v}\left(01^{1} 0\right)=0.494$, from the other three isotopologues and the $\mathrm{G}_{\mathrm{v}}\left(02^{0} 0\right)$ value for ${ }^{32} \mathrm{~S}^{12} \mathrm{C}^{33} \mathrm{~S}_{2}$.

\subsection{Methyl Iodide (IUPAC name iodomethane)}

Methyl iodide is a new species on the HITRAN database, molecule \#54. The TIPS were determined from 1-5000 K using the product approximation with the 2014 Codata constants for two isotopologues: ${ }^{12} \mathrm{CH}_{3}{ }^{127} \mathrm{I}$ and ${ }^{13} \mathrm{CH}_{3}{ }^{127} \mathrm{I}$. The rotational and vibrational constants for 
${ }^{12} \mathrm{CH}_{3}{ }^{127} \mathrm{I}$ are from Perrin et al. [154]. For ${ }^{13} \mathrm{CH}_{3}{ }^{127} \mathrm{I}$ the rotational constants are from Alanko [155] and the vibrational term values are from Perrin et al. [154], Alanko [155], and some scaled from Alanko's combination band values. The rotational partition sums were determined using McDowell's symmetric-top analytical formula and the vibrational partition sums were computed using the HOA. There is a $6 \%$ difference in $Q(296 \mathrm{~K})$ between ${ }^{12} \mathrm{CH}_{3}{ }^{127} \mathrm{I}$ and ${ }^{13} \mathrm{CH}_{3}{ }^{127} \mathrm{I}$, which can be compared to a $0.07 \%$ difference between $Q\left({ }^{12} \mathrm{CH}_{3} \mathrm{D}\right)$ and $Q\left({ }^{13} \mathrm{CH}_{3} \mathrm{D}\right)$ at $296 \mathrm{~K}$. To confirm this difference, a variational calculation was performed using a very small basis set up to $\mathrm{J}=80, Q(296 \mathrm{~K})$ computed by the product approximation, and indeed the $6 \%$ difference was confirmed.

\subsection{Nitrogen Trifluoride}

The nitrogen trifluoride isotopologue, ${ }^{14} \mathrm{~N}^{19} \mathrm{~F}_{3}$, is a new species on the HITRAN database, molecule $\# 55$. $\mathrm{NF}_{3}$ belongs to the $\mathrm{C}_{3 \mathrm{v}}$ point group at the equilibrium configuration and possesses 4 fundamental vibrations: $v_{1}\left(A_{1}\right), v_{2}\left(A_{1}\right), v_{3}(E)$ and $v_{4}(E)$. Since $N_{3}$ is a semirigid molecule, the normal mode coordinates were employed to build the Hamiltonian in the Watson formalism [49] using the reduction technique described by Rey et al. [51]. For this work, both the kinetic energy part and the potential energy surface reported by Egorov et al. [156], have been expanded to order 14 in normal coordinates and reduced to order 7. For a full account of symmetry, the use of irreducible tensor operators turned out to be an optimal choice [157]. Concerning the computation of energy levels, the $\mathrm{J}=0$ vibrational problem was first solved using a direct product of harmonic oscillator functions, resulting in 6975,5985 and 12915 functions for the symmetry blocks $\mathrm{A}_{1}, \mathrm{~A}_{2}$ and $\mathrm{E}$, respectively. For $\mathrm{J}>0$, a set of vibrational reduced eigenfunctions obtained from the projection technique [51] was introduced to drastically reduce dimensionality of the full problem, 
making thus calculations feasible even for high $\mathrm{J}$ values. For this work, rovibrational term values were computed variationally up to $J_{\max }=80$. These term values allow a check of $Q(T)$ data from analytical models.

In the partition sum calculations that follow the 2014 Codata constants were used. First the TIPS were determined using the term values discussed above. Because the term values are only complete to $\sim 1700 \mathrm{~cm}^{-1}$ it is not expected that the resulting partition sums will be converged at high temperatures. Next, the TIPS were calculated from 1-5000 K using the product approximation with $Q_{r o t}$ determined using McDowell's symmetric-top formula with the constants of [158] and $Q_{v i b}$ determined via the HOA with vibrational constants from Egorov et al. [156]. The comparison of the direct sum and analytical model $Q(T)$ s is shown in Fig. 4, where the percent difference (blue solid line) between the direct summation TIPS, $Q(D S)$ minus the TIPS form the product approximation, $Q(P A)$ is plotted versus temperature from 1-750 K. The results give a $0.034 \%$ difference at $296 \mathrm{~K}$, a $-1.1 \%$ difference at $500 \mathrm{~K}$, and grow rapidly with temperature because $Q(D S)$ is not converged at $J_{\max }=80$ for $T>350 \mathrm{~K}$. The TIPS from the analytical models are used.

Insert Fig 4 Here

\subsection{Propyne}

The TIPS for the ${ }^{12} \mathrm{C}_{3} \mathrm{H}_{4}$ isotopologue of propyne were recalculated from 1-5000 K using the 2014 Codata constants. Using McDowell's analytical formula for symmetric-tops and the constants of Cazzoli and Puzzarini [159] the rotational partition sums were calculated. Using the constants provided by Pracna [160] the vibrational partition sums were calculated via the HOA. 


\subsection{Methyl Radical}

The TIPS for the methyl radical, ${ }^{12} \mathrm{CH}_{3}$, were recalculated from 1-5000 K using the 2014 Codata constants. Using the molecular constants of Yamada et al. [161], the energy levels of the methyl radical, a planar symmetric top, were computed for states up to $J=50$. The terms values are complete to $17,545 \mathrm{~cm}^{-1}$ and were used to compute $Q_{r o t}$. The vibrational partition sums were determined using the HOA and the following fundamental frequencies: $v_{1}=3004.43 \mathrm{~cm}^{-1}$ [162], $v_{2}=606.4531 \mathrm{~cm}^{-1}[161], v_{3}=3160.821 \mathrm{~cm}^{-1}$ [163], and $v_{4}=1397 \mathrm{~cm}^{-1}$ [164]. The final TIPS were from the product approximation.

\section{RAPID RECALL OF THE TIPS}

The total internal partition sums will be made available in tabular form for all isotopologues of this study at the HITRAN website (www.hitran.org) and at the website of the corresponding author (http://faculty.uml.edu/Robert Gamache). To be useful to applications that require the TIPS at various temperatures, codes that make a rapid recall of the TIPS as a function of molecule, isotopologue, and temperature are needed. As discussed above, in earlier works [12-18], a FORTRAN code, e.g., TIPS_2011.for, was made openly available to the scientific community and starting in 2017 a python code [19] was also made available to the community. At the websites listed above, the following codes are available: TIPS_2021_v1p0.for, BD_TIPS_2021_v1p0.for and TIPS_2021_v1p0.py. TIPS_2021_v1p0.for is a stand-alone program that queries the user for molecule, isotopologue, and temperature and then returns $Q(T)$ for that species. BD_TIPS_2021_v1p0.for is a subroutine version that users can insert into their 
codes to obtain $Q(T)$ for their applications. These codes store the TIPS from $1-20 \mathrm{~K}$ in $1 \mathrm{~K}$ intervals and then from $22 \mathrm{~K}$ to $T_{\max }$ in $2 \mathrm{~K}$ steps. The algorithms recall the TIPS by first checking if the requested temperature is one of the stored temperatures. If so, the TIPS value is returned, otherwise linear interpolation between the 2 points surrounding the requested temperature is done and that value returned.

For TIPS_2021_v1p0.py, python libraries have been created from the TIPS data. The data are stored similarly to the FORTRAN routines and linear interpolation used. Note, this interpolation method has been shown to have less than 0.001 absolute average percent difference. The library names are "molecule \#", 'ISO\#”.QTpy, where the molecule number and isotopologue number are given in Table 1. For example, the dictionary for the ${ }^{13} \mathrm{C}^{16} \mathrm{O}_{2}$ isotopologue of water is 2_2.QTpy. All the dictionaries are stored in a folder labeled /QTpy/. The code, TIPS_2021.py, queries the user for molecule, isotopologue, and temperature; then selects the proper dictionary and extracts $Q(T)$ with a key constructed from the input.

Extracting individual subroutines out of BD_TIPS_2021_v1p0.for allows researchers to create custom codes for applications on a subset of molecules and isotopologues. Similar routines can be made with the python code by hardwiring the molecule number and isotopologue number into the dictionary definition.

Caution should be used if previous versions of the TIPS codes are to be used with the 2021 versions as some of the molecule numbers have changed to retain compatibility with HITRAN. These can be found by comparing Table 1 from Ref. [19] to Table 1 presented here.

The codes all use the MIT license (see codes for details) and can be downloaded at http://faculty.uml.edu/Robert_Gamache, at www.HITRAN.org or at zenodo.org (10.5281/zenodo.4708099). 


\section{SUMMARY}

Total internal partition sums are presented for all the molecules (55) and isotopologues (179) in the line-by-line portion of the HITRAN2020 database and for additional molecules/isotopologues $\left(\mathrm{C}_{3} \mathrm{H}_{4}\right.$ and $\left.\mathrm{CH}_{3}\right)$ of astrophysical interest. All previous calculations of the TIPS have been updated using $h, k$, and $c$ from the 2014 Codata physical constants. New calculations are presented for a number of molecules (13), isotopologues (28) that are either new to HITRAN or for which improvements were possible. The TIPS were calculated from $1 \mathrm{~K}$ to $T_{\max }$, where $T_{\max }$ is determined by the convergence of the TIPS for each isotopologue. Tables of the TIPS are available as supplemental information, at www.HITRAN.org and http://Faculty.uml.edu/Robert_Gamache. Rapid recall of the TIPS can be achieved using the FORTRAN codes TIPS_2021_v1p0.for and BD_TIPS_2021_v1p0.for or using the python code TIPS_2021_v1p0.py, which are available at the above web sites.

\section{Acknowledgements}

Research at the University of Massachusetts Lowell was supported by the National Science Foundation through Grant No. AGS-1622676. V.T. and O.E. acknowledge the support for the ozone studies from Russian Science Foundation RNF grant no. 19-12-00171. GSMA laboratory acknowledges the support from LIA "SAMIA" French-Russian collaboration program and ROMEO computer center of the Champagne-Ardennes region, France. The development of 
the HITRAN database is supported through NASA grants NNX17AI78G, NNX16AG51G and 80NSSC20K0962.

\section{References}

[1] Hill Tl. An Introduction to Statistical Thermodynamics, Addison-Wesley Publishing Company, Inc., Reading, Massachusetts, USA, 1960.

[2] Gamache RR, Goldman A. Einstein A Coefficient, integrated band intensity, and population factors Application to the $\mathrm{a}^{1} \Delta_{\mathrm{g}}-X^{3} \Sigma_{\mathrm{g}}{ }^{-}(0,0) \mathrm{O}_{2}$ band, J. Quant Spectrosc. Radiat. Transfer 2001; 69: 389-401.

[3] Rothman LS, Gordon IE, Babikov Y, Barbe A, Chris Benner D, Bernath PF, Birk M, Bizzocchi L, Boudon V, Brown LR, Campargue A, Chance K, Cohen EA, Coudert LH, Devi VM, Drouin BJ, Fayt A, Flaud JM, Gamache RR, Harrison JJ, Hartmann JM, Hill C, Hodges JT, Jacquemart D, Jolly A, Lamouroux J, Le Roy RJ, Li G, Long DA, Lyulin OM, Mackie CJ, Massie ST, Mikhailenko S, Müller HSP, Naumenko OV, Nikitin AV, Orphal J, Perevalov V, Perrin A, Polovtseva ER, Richard C, Smith MAH, Starikova E, Sung K, Tashkun S, Tennyson J, Toon GC, Tyuterev VG, Wagner G. The HITRAN2012 molecular spectroscopic database, Journal of Quantitative Spectroscopy and Radiative Transfer 2013; 130: 4-50.

[4] Gordon IE, Rothman LS, Hill C, R.V.Kochanov, Tan Y, Bernath PF, Birk M, Boudon V, Campargue A, Chance KV, Drouin BJ, Flaud J-M, Gamache RR, Jacquemart D, Perevalov VI, Perrin A, Smith M-AH, Tennyson J, Tran H, Tyuterev VG, Toon GC, Hodges JT, Shine KP, Barbe A, Csaszar A, Devi MV, Furtenbacher T, Harrison JJ, Jolly A, Johnson T, Karman T, Kleiner I, Kyuberis A, Loos J, Lyulin O, Mikhailenko SN, Moazzen-Ahmadi N, Müller HSP, Naumenko O, Nikitin A, Polyansky O, Rey M, Rotger M, Sharpe S, Sung K, Starikova E, Tashkun SA, Auwera JV, Wagner G, Wilzewski J, Wcisło P, Yu S, Zak E. The HITRAN2016 Molecular Spectroscopic Database, Journal of Quantitative Spectroscopy and Radiative Transfer 2017; 203: 3-69.

[5] Jacquinet-Husson N, Armante R, Scott NA, Chédin A, Crépeau L, Boutammine C, Bouhdaoui A, Crevoisier C, Capelle V, Boonne C, Poulet-Crovisier N, Barbe A, Chris Benner D, Boudon V, Brown LR, Buldyreva J, Campargue A, Coudert LH, Devi VM, Down MJ, Drouin BJ, Fayt A, Fittschen C, Flaud JM, Gamache RR, Harrison JJ, Hill C, Hodnebrog Ø, Hu SM, Jacquemart D, Jolly A, Jiménez E, Lavrentieva NN, Liu AW, Lodi L, Lyulin OM, Massie ST, Mikhailenko S, Müller HSP, Naumenko OV, Nikitin A, Nielsen CJ, Orphal J, Perevalov VI, Perrin A, Polovtseva E, Predoi-Cross A, Rotger M, Ruth AA, Yu SS, Sung K, Tashkun SA, Tennyson J, Tyuterev VG, Vander Auwera J, Voronin BA, Makie A. The 2015 edition of the GEISA spectroscopic database, Journal of Molecular Spectroscopy 2016; 327: 31-72.

[6] Gamache RR, Vispoel B. On the temperature dependence of half-widths and line shifts for molecular transitions in the microwave and infrared regions, J. Quant Spectrosc. Radiat. Transfer 2018; 217: 440-52. 
[7] Sauval AJ, Tatum JB. A Set of Partition Functions and Equilibrium Constants for 300 Diatomic Molecules of Astrophysical Interest, Astrophys. J. Suppl. Ser. 1984; 56: 193209.

[8] Irwin AW. Astronomy and Astrophysics: Refined diatomic partition functions I. Calculational methods and $\mathrm{H}_{2}$ and $\mathrm{CO}$ results, Astron. Astrophys. 1987; 182: 348-58.

[9] Irwin AW. The partition functions of JANAF polyatomic molecules that significantly affect the stellar atmospheric equations of state, Astron. Astrophys. Suppl. Ser. 1988; 74: $145-60$.

[10] Chase JMW, Davies CA, Downey JJR, Frurip DJ, McDonald RA, Syverud AN. JANAF Thermochemical Tables Third Edition, J. Phys. Chem. Ref. Data 1985; 14, Suppl. 1: 11856.

[11] Barklem PS, Collet R. Partition functions and equilibrium constants for diatomic molecules and atoms of astrophysical interest, A\&A 2016; 588: A96.

[12] Gamache RR, Hawkins RL, Rothman LS. Total Internal Partition Sums in the Temperature Range 70-3000K: Atmospheric Linear Molecules, J. Mol. Spectrosc. 1990; 142: 205-19.

[13] Gamache RR, Kennedy S, Hawkins R, Rothman LS. Total Internal Partition Sums for Molecules in the Terrestrial Atmosphere, J. Mol. Struct. 2000; 517-518: 413-31.

[14] Goldman A, Gamache RR, Perrin A, Flaud J-M, Rinsland CP, Rothman LS. HITRAN Partition Functions and Weighted Transition Probabilities, J. Quant. Spectrosc. Radiat. Transfer 2000; 66: 455-86.

[15] Fischer J, Gamache RR. Total Internal Partition Sums for Molecules of Astrophysical Interest, J. Quant Spectrosc. Radiat. Transfer 2002; 74: 263-72.

[16] Fischer J, Gamache RR. Partition Sums for Non-Local Thermodynamic Equilibrium Applications, J. Quant Spectrosc. Radiat. Transfer 2002; 74: 273-84.

[17] Fischer J, Gamache RR, Goldman A, Rothman LS, Perrin A. Total Internal Partition Sums for Molecular Species on the 2000 Edition of the HITRAN Database, J. Quant. Spectrosc. Radiat. Transfer 2003; 82: 401-12.

[18] Laraia AL, Gamache RR, Lamouroux J, Gordon IE, Rothman LS. Total internal partition sums to support planetary remote sensing, Icarus 2011; 215: 391-400.

[19] Gamache RR, Roller C, Lopes E, Gordon IE, Rothman LS, Polyansky OL, Zobov NF, Kyuberis AA, Tennyson J, Yurchenko SN, Császár AG, Furtenbacher T, Huang X, Schwenke DW, Lee TJ, Drouin BJ, Tashkun SA, Perevalov VI, Kochanov RV. Total internal partition sums for 166 isotopologues of 51 molecules important in planetary atmospheres: Application to HITRAN2016 and beyond, Journal of Quantitative Spectroscopy and Radiative Transfer 2017; 203: 70-87.

[20] Rothman LS, Gamache RR, Goldman A, Brown LR, Toth RA, Pickett HM, Poynter RL, Flaud J-M, Camy-Peyret C, Barbe A, Husson N, Rinsland CP, Smith MAH. The HITRAN Database: 1986 Edition, Appl. Opt. 1987; 26: 4058-97.

[21] Rothman LS, Gamache RR, R.H.Tipping, Rinsland CP, Smith MAH, Benner DC, Devi VM, Flaud J-M, C.Camy-Peyret, A.Perrin, A.Goldman, S.T.Massie, L.R.Brown, Toth RA. The Hitran Molecular Database: Editions of 1991 And 1992, J. Quant. Spectrosc. Radiat. Transfer 1992; 48: 469-507.

[22] Rothman LS, Rinsland CP, Goldman A, Massie ST, Edwards DP, Flaud J-M, Perrin A, Camy-Peyret C, V.Dana, Mandin JY, J.Schroeder, Mccann A, R.R.Gamache, Wattson RB, K. Yoshino, Chance KV, Jucks KW, Brown LR, Nemtchinov V, Varanasi P. The 
Hitran Molecular Spectroscopic Database and Hawks( Hitran Atmospheric Workstation), J. Quant. Spectrosc. Radiat. Transfer 1998; 60: 665-710.

[23] Rothman LS, Barbe A, Benner DC, Brown LR, Camy-Peyret C, Carleer MR, Chance K, Clerbaux C, Dana V, Devi VM, Fayt A, Flaud J-M, Gamache RR, Goldman A, Jacquemart D, Jucks KW, Lafferty WJ, Mandin J-Y, Massie ST, Nemtchinov V, Newnham DA, Perrin A, Rinsland CP, Schroeder J, Smith KM, Smith MAH, Tang K, Toth RA, Auwera JV, Varanasi P, Yoshino K. The HITRAN molecular spectroscopic database: edition of 2000 including updates through 2001, J. Quant. Spectrosc. Radiat. Transfer 2003; 82: 5-44.

[24] Rothman LS, Jacquemart D, Barbe A, Benner DC, Birk M, Brown LR, Carleer MR, Chackerian C, Jr., Chance K, Coudert LH, Dana V, Devi VM, Flaud J-M, Gamache RR, Goldman A, Hartmann J-M, Jucks KW, Maki AG, Mandin J-Y, Massie ST, Orphal J, Perrin A, Rinsland CP, Smith MAH, Tennyson J, Tolchenov RN, Toth RA, Vander Auwera J, Varanasi P, Wagner G. The HITRAN 2004 Molecular Spectroscopic Database, J. Quant. Spectrosc. Radiat. Transfer 2005; 96: 139-204.

[25] Rothman LS, Gordon IE, Barbe A, Benner DC, Bernath PF, Birk M, Boudon V, Brown LR, Campargue A, Champion J-P, Chance K, Coudert LH, Dana V, Devi VM, Fally S, Flaud J-M, Gamache RR, Goldman A, Jacquemart D, Kleiner I, Lacome N, Lafferty WJ, Mandin J-Y, Massie ST, Mikhailenko SN, Miller CE, Moazzen-Ahmadi N, Naumenko OV, Nikitin AV, Orphal J, Perevalov VI, Perrin A, Predoi-Cross A, Rinsland CP, Rotger M, Simeckova M, Smith MAH, Sung K, Tashkun SA, Tennyson J, Toth RA, Vandaele AC, Auwera JV. The HITRAN 2008 molecular spectroscopic database, J. Quant. Spectrosc. Radiat. Transfer 2009; 110: 533-72.

[26] Szidarovszky T, Császár AG. Toward accurate thermochemistry of the ${ }^{24} \mathrm{MgH},{ }^{25} \mathrm{MgH}$, and ${ }^{26} \mathrm{MgH}$ molecules at elevated temperatures: Corrections due to unbound states, The Journal of Chemical Physics 2015; 142: 014103.

[27] Furtenbacher T, Szidarovszky T, Hruby J, Kyuberis AA, Zobov NF, Polyansky OL, Tennyson J, Császár AG. Definitive ideal-gas thermochemical functions of the $\mathrm{H}_{2}{ }^{16} \mathrm{O}$ molecule, J. Phys. Chem. Ref. Data 2016; 45: 043104.

[28] Simkó I, Furtenbacher T, Hrubý J, Zobov NF, Polyansky OL, Tennyson J, Gamache RR, Szidarovszky T, Dénes N, Császár AG. Recommended ideal-gas thermochemical functions for heavy water and its substituent isotopologues, J. Phys. Chem. Ref. Data in press 2017;

[29] Mohr PJ, Newell DB, Taylor BN. CODATA recommended values of the fundamental physical constants: 2014, Rev. Mod. Phys. 2016; 88: 035009.

[30] Herzberg G. Molecular Spectra and Molecular Structure II. Infrared and Raman Spectra of Polyatomic Molecules, D. Van Nostrand Company, Inc. New Jersey, 1960.

[31] McDowell RS. Rotational partition fuctions for linear molecules, J. Chem. Phys 1988; 88: $356-61$.

[32] McDowell RS. Rotational partition functions for symmetric-top molecules, J. Chem. Phys. 1990; 93: 2801-11.

[33] McDowell RS. Rotational partition functions for spherical-top molecules, Journal of Quantitative Spectroscopy and Radiative Transfer 1987; 38: 337-46.

[34] Watson JKG. The asymptotic asymmetric-top rotational partition function, Molecular Physics 1988; 65: 1377-97.

[35] Huang X, Freedman RS, Tashkun SA, Schwenke DW, Lee TJ. Semi-empirical ${ }^{12} \mathrm{C}^{16} \mathrm{O}_{2}$ 
IR line lists for simulations up to $1500 \mathrm{~K}$ and $20,000 \mathrm{~cm}^{-1}$, Journal of Quantitative Spectroscopy and Radiative Transfer 2013; 130: 134-46.

[36] Huang X, Gamache RR, Freedman RS, Schwenke DW, Lee TJ. Reliable InfraRed Line Lists for $13 \mathrm{CO}_{2}$ Isotopologues up to $\mathrm{E}^{\prime}=18,000 \mathrm{~cm}^{-1}$ and $1500 \mathrm{~K}$, with Line Shape Parameters, Journal of Quantitative Spectroscopy and Radiative Transfer 2014; 147: 13444.

[37] Huang X, Schwenke DW, Tashkun SA, Lee TJ. An isotopic-independent highly accurate potential energy surface for $\mathrm{CO}_{2}$ isotopologues and an initial ${ }^{12} \mathrm{C}^{16} \mathrm{O}_{2}$ infrared line list, $\mathrm{J}$. Chem. Phys. 2012; 136: 124311.

[38] Birk M, Wagner G, Gordon IE, Drouin BJ. Ozone intensities in the rotational bands, Journal of Quantitative Spectroscopy and Radiative Transfer 2019; 226: 60-5.

[39] Pickett HM, Poynter RL, Cohen EA, Delitsky ML, Pearson JC, MÜLler HSP. SUBMILLIMETER, MILLIMETER, AND MICROWAVE SPECTRAL LINE CATALOG, Journal of Quantitative Spectroscopy and Radiative Transfer 1998; 60: 88390.

[40] Babikov YL, Mikhailenko SN, Barbe A, Tyuterev VG. S\&MPO - An information system for ozone spectroscopy on the WEB, Journal of Quantitative Spectroscopy and Radiative Transfer 2014; 145: 169-96.

[41] Tyuterev V, Kochanov R, Starikova E, Kokoouline V, Egorov O, Alijah A, Gamache R, Temperature dependence of the ozone partition function computed from experimental levels and ab initio potential function 2021: To be submitted to JQSRT.

[42] Barbe A, Mikhailenko S, Starikova E, De Backer MR, Tyuterev VG, Mondelain D, Kassi S, Campargue A, Janssen C, Tashkun S, Kochanov R, Gamache R, Orphal J. Ozone spectroscopy in the electronic ground state: High-resolution spectra analyses and update of line parameters since 2003, Journal of Quantitative Spectroscopy and Radiative Transfer 2013; 130: 172-90.

[43] Tyuterev VG, Kochanov RV, Tashkun SA. Accurate ab initio dipole moment surfaces of ozone: First principle intensity predictions for rotationally resolved spectra in a large range of overtone and combination bands, The Journal of Chemical Physics 2017; 146: 064304.

[44] Kokoouline V, Lapierre D, Alijah A, Tyuterev V. Localized and delocalized bound states of the main isotopologue $48 \mathrm{O} 3$ and of 18O-enriched $50 \mathrm{O} 3$ isotopomers of the ozone molecule near the dissociation threshold, Physical Chemistry Chemical Physics 2020; 22: 15885-99.

[45] Tyuterev VG, Kochanov RV, Tashkun SA, Holka F, Szalay PG. New analytical model for the ozone electronic ground state potential surface and accurate ab initio vibrational predictions at high energy range, The Journal of Chemical Physics 2013; 139: 134307.

[46] Tashkun SA, Perevalov VI, Lavrentieva NN. NOSD-1000, the high-temperature nitrous oxide spectroscopic databank, Journal of Quantitative Spectroscopy and Radiative Transfer 2016; 177: 43-8.

[47] Toth RA. Frequencies of $\mathrm{N}_{2} \mathrm{O}$ in the 1100 - to $1440-\mathrm{cm}^{-1}$ region $1440-\mathrm{cm}^{-1}$ region, J. Opt. Soc. Am. B 1986; 3: 1263-81.

[48] Li G, Gordon IE, Rothman LS, Tan Y, Hu S-M, Kassi S, Campargue A, Medvedev ES. Rovibrational Line Lists for Nine Isotopologues of the CO Molecule in the $\mathrm{X}^{1} \Sigma^{+}$Ground Electronic State, The Astrophysical Journal Supplement Series 2015; 216: 15.

[49] Watson JKG. Simplification of the Molecular vibration-rotation Hamiltonian, Molecular 
Physics 1968; 15: 479-90.

[50] Nikitin AV, Rey M, Tyuterev VG. Rotational and vibrational energy levels of methane calculated from a new potential energy surface, Chemical Physics Letters 2011; 501: 179-86.

[51] Rey M, Chizhmakova IS, Nikitin AV, Tyuterev VG. Understanding global infrared opacity and hot bands of greenhouse molecules with low vibrational modes from firstprinciples calculations: the case of $\mathrm{CF}_{4}$, Phys. Chem. Chem. Phys. 2018; 20: 21008-33.

[52] Rey M, Nikitin AV, Tyuterev VG. Complete nuclear motion Hamiltonian in the irreducible normal mode tensor operator formalism for the methane molecule, The Journal of Chemical Physics 2012; 136: 244106.

[53] Rey M, Nikitin AV, Tyuterev VG. Accurate first-principles calculations for ${ }^{12} \mathrm{CH}_{3} \mathrm{D}$ infrared spectra from isotopic and symmetry transformations, The Journal of Chemical Physics 2014; 141: 044316.

[54] Rey M, Nikitin AV, Tyuterev VG. Accurate Theoretical Methane Line Lists in the Infrared up to $3000 \mathrm{~K}$ and Quasi-continuum Absorption/Emission Modeling for Astrophysical Applications, The Astrophysical Journal 2017; 847: 105 (19pp).

[55] Dang-Nhu M, Pine AS, Robiette AG. Spectral intensities in the $v 3$ bands of $12 \mathrm{CH} 4$ and 13CH4, Journal of Molecular Spectroscopy 1979; 77: 57-68.

[56] Nikitin AV, Krishna BM, Rey M, Tashkun SA, Tyuterev VG. Methane high-temperature partition function from contact transformations and variational calculations, Journal of Quantitative Spectroscopy and Radiative Transfer 2015; 167: 53-63. Erratum: Journal of Quantitative Spectroscopy and Radiative Transfer, 198, p. 187.

[57] Tyuterev V, Tashkun S, Rey M, Kochanov R, Nikitin A, Delahaye T. Accurate Spectroscopic Models for Methane Polyads Derived from a Potential Energy Surface Using High-Order Contact Transformations, The Journal of Physical Chemistry A 2013; 117: $13779-805$.

[58] Tarrago G, Delaveau M, Fusina L, Guelachvili G. Absorption of 12CH3D at 6-10 $\mu \mathrm{m}$ : Triad v3, v5, v6, Journal of Molecular Spectroscopy 1987; 126: 149-58.

[59] Ulenikov ON, Onopenko GA, Tyabaeva NE, Anttila R, Alanko S, Schroderus J. Rotational Analysis of the Ground State and the Lowest Fundamentals v3, v5, and v6 of 13CH3D, Journal of Molecular Spectroscopy 2000; 201: 9-17.

[60] Yu S, Drouin BJ, Miller CE. High resolution spectral analysis of oxygen. IV. Energy levels, partition sums, band constants, RKR potentials, Franck-Condon factors involving the $\mathrm{X}^{3} \Sigma_{\mathrm{g}}^{-}, \mathrm{a}^{1} \Delta_{\mathrm{g}}$ and $\mathrm{b}^{1} \Sigma_{\mathrm{g}}^{+}$states, The Journal of Chemical Physics 2014; 141: 174302.

[61] Rothman LS, Gordon IE, Barber RJ, Dothe H, Gamache RR, Goldman A, Perevalov VI, Tashkun SA, Tennyson J. HITEMP, the High-Temperature Molecular Spectroscopic Database, J. Quant. Spectrosc. Radiat. Transfer 2010; 111: 2139-50.

[62] Hargreaves RJ, Gordon IE, Rothman LS, Tashkun SA, Perevalov VI, Lukashevskaya AA, Yurchenko SN, Tennyson J, Müller HSP. Spectroscopic line parameters of NO, NO2, and N2O for the HITEMP database, Journal of Quantitative Spectroscopy and Radiative Transfer 2019; 232: 35-53.

[63] Pine AS, Dresselhaus G, Palm B, Davies RW, Clough SA. Analysis of the 4- $\mathrm{mm} \mathrm{n}_{1}+\mathrm{n}_{3}$ Combination Band of $\mathrm{SO}_{2}$, J. Mol. Spectrosc. 1977; 67: 386-415.

[64] Lafferty WJ, Pine AS, Flaud JM, Camypeyret C. The 2v3 Band of 32S16O2: Line Positions and Intensities, Journal of Molecular Spectroscopy 1993; 157: 499-511.

[65] Ulenikov ON, Bekhtereva ES, Krivchikova YV, Zamotaeva VA, Buttersack T, Sydow C, 
Bauerecker S. Study of the high resolution spectrum of 32S16O18O: The $v 1$ and $v 3$ bands, Journal of Quantitative Spectroscopy and Radiative Transfer 2016; 168: 29-39.

[66] Blake TA, Flaud JM, Lafferty WJ. First analysis of the rotationally-resolved $v 2$ and 2v2$\checkmark 2$ bands of sulfur dioxide, 33S16O2, Journal of Molecular Spectroscopy 2017; 333: 1922.

[67] Perrin A, Flaud J-M, Peyret CC-, Carli B, Carlotti M. The far infrared spectrum of ${ }^{14} \mathrm{~N}^{16} \mathrm{O}_{2}$ Electron spin-rotation and hyperfine Fermi contact resonances in the ground state, Molecular Physics 1988; 63: 791-810.

[68] Norton RH, Rinsland CP. ATMOS data processing and science analysis methods, Applied Optics 1991; 30: 389-400.

[69] Yurchenko SN, Barber RJ, Tennyson J. A variationally computed line list for hot NH3, Monthly Notices of the Royal Astronomical Society 2011; 413: 1828-34.

[70] Yurchenko SN. A theoretical room-temperature line list for ${ }^{15} \mathrm{NH}_{3}$, Journal of Quantitative Spectroscopy and Radiative Transfer 2015; 152: 28-36.

[71] Brooke JSA, Bernath PF, Western CM, Sneden C, Afşar M, Li G, Gordon IE. Line strengths of rovibrational and rotational transitions in the ground state of $\mathrm{OH}$, Journal of Quantitative Spectroscopy and Radiative Transfer 2016; 168: 142-57.

[72] Beaudet RA, Poynter RL. Mirowave Spectra of Molecules of Astrophysical Interest. XII. Hydroxyl Radical, J. Phys. Chem.Ref. Data 1978; 7: 311-3.

[73] Li G, Gordon IE, Le Roy RJ, Hajigeorgiou PG, Coxon JA, Bernath PF, Rothman LS. Reference spectroscopic data for hydrogen halides. Part I: Construction and validation of the ro-vibrational dipole moment functions, Journal of Quantitative Spectroscopy and Radiative Transfer 2013; 121: 78-90.

[74] Endo Y, Saito S, Hirota E. Microwave Spectroscopy of the CCl Radical, J. Mol. Spectrosc. 1982; 94: 199-207.

[75] Cohen EA, Pickett HM, Geller M. The Submillimeter Spectrum of ClO, J. Mol. Spectrosc. 1984; 106: 430-5.

[76] Maki AG. Microwave Spectra of Molecules of Atrophysical Interest VI. Carbonyl Sulfide and Hydrogen Cyanide, Journal of Physical and Chemical Reference Data 1974; 3: 221-44.

[77] Burenin AV, Karyakin EN, Krupnov AF, Shapin SM, Val'dov AN. Submillimeter microwave spectrum and spectroscopic constants of the OCS molecule: Less abundant isotopic species of the molecule, Journal of Molecular Spectroscopy 1981; 85: 1-7.

[78] Hunt N, Foster SC, Johns JWC, McKeller ARW. High- Resolution Spectroscopy of 16 Bands of OCS in the Region 1975-2140 $\mathrm{cm}^{-1}$ for Diode Laser Calibration, J. Mol. Spectrosc. 1985; 111: 42-53.

[79] Blanquet G, Walrand J, Courtoy CP, Fayt A. The $v 3$ band of $16 \mathrm{O} 12 \mathrm{C} 34 \mathrm{~S}$ and 16O13C34S, Journal of Molecular Spectroscopy 1980; 81: 473-9.

[80] Winnewisser G, Cornet RA, Birss FW, Gordon RM, Ramsay DA, Till SM. Determination of the ground state rotational constants for formaldehyde: $\mathrm{H} 212 \mathrm{CO}$ and H213CO, Journal of Molecular Spectroscopy 1979; 74: 327-9.

[81] Lovas FJ. Rotational constants for isotopologues of hypochlorous acid, private communication, National Institute of Standards and Technology, 1989.

[82] Le Roy RJ, Huang Y, Jary C. An accurate analytic potential function for ground-state N2 from a direct-potential-fit analysis of spectroscopic data, The Journal of Chemical Physics 2006; 125: 164310. 
[83] Harris GJ, Larner FC, Tennyson J, Kaminsky BM, Pavlenko YV, Jones HRA. A H13CN/HN13C linelist, model atmospheres and synthetic spectra for carbon stars, Monthly Notices of the Royal Astronomical Society 2008; 390: 143-8.

[84] Harris GJ, Tennyson J, Kaminsky BM, Pavlenko YV, Jones HRA. Improved HCN/HNC linelist, model atmospheres and synthetic spectra for WZ Cas, Monthly Notices of the Royal Astronomical Society 2006; 367: 400-6.

[85] Lauro CD, Alamichel C. Rotational Analysis of the $\mathrm{n}_{2}+\mathrm{n}_{6}{ }^{ \pm 1}, \mathrm{n}_{5}+\mathrm{n}_{6}{ }^{ \pm 1}$, and $2 \mathrm{n}_{3}+\mathrm{n}_{6}^{ \pm 1}$ Interacting Infrared Bands of Methyl Chloride, J. Mol. Spectrosc. 1980; 81: 390-412.

[86] Al-Refaie AF, Ovsyannikov RI, Polyansky OL, Yurchenko SN, Tennyson J. A variationally calculated room temperature line-list for $\mathrm{H}_{2} \mathrm{O} 2$, Journal of Molecular Spectroscopy 2015; 318: 84-90.

[87] Amyay B, Herman M, Fayt A, Campargue A, Kassi S. Acetylene, ${ }^{12} \mathrm{C}_{2} \mathrm{H}_{2}$ : Refined analysis of CRDS spectra around $1.52 \mu \mathrm{m}$, Journal of Molecular Spectroscopy 2011; 267: 80-91.

[88] Hietanen J, Kauppinen J. High-resolution infrared spectrum of acetylene in the region of the bending fundamental v 5, Molecular Physics 1981; 42: 411-23.

[89] Jolly A, Benilan Y, Cané E, Fusina L, Tamassia F, Fayt A, Robert S, Herman M. Measured integrated band intensities and simulated line-by-line spectra for ${ }^{12} \mathrm{C}_{2} \mathrm{HD}$ between 25 and $2.5 \mu \mathrm{m}$, and new global vibration-rotation parameters for the bending vibrations, J. Quant Spectrosc. Radiat. Transfer 2008; 109: 2846-56.

[90] Duncan JL, McKean DC, Bruce AJ. Infrared Spectroscopic Studies of Partially Deuterated Ethanes and the $\mathrm{r}_{0}, \mathrm{r}_{\mathrm{z}}, \mathrm{r}_{\mathrm{e}}$ Structures, Journal of Molecular Spectroscopy 1979; 74: 361-74.

[91] Daly AM, Drouin BJ, Pearson JC, Sung K, Brown LR, Mantz A, Smith MAH. The v17 band of C2H5D from 770 to $880 \mathrm{~cm}-1$, Journal of Molecular Spectroscopy 2015; 316: 110.

[92] Doney KD, Kofman V, Villanueva G, Sung K. A new model of monodeuterated ethane (C2H5D) spectrum: Enabling sensitive constraints on the D/H in ethane emission in comets, Journal of Quantitative Spectroscopy and Radiative Transfer 2020; 255: 107225.

[93] Kondo S, Saëki S. Infrared absorption intensities of ethane and propane, Spectrochimica Acta Part A: Molecular Spectroscopy 1973; 29: 735-51.

[94] Sousa-Silva C, Hesketh N, Yurchenko SN, Hill C, Tennyson J. High temperature partition functions and thermodynamic data for ammonia and phosphine, Journal of Quantitative Spectroscopy and Radiative Transfer 2014; 142: 66-74.

[95] Faye M, Boudon V, Loëte M, Roy P, Manceron L. The high overtone and combination levels of SF6 revisited at Doppler-limited resolution: A global effective rovibrational model for highly excited vibrational states, Journal of Quantitative Spectroscopy and Radiative Transfer 2017; 190: 38-47.

[96] Rey M, Chizhmakova IS, Nikitin AV, Tyuterev VG. Towards a complete elucidation of the ro-vibrational band structure in the SF6 infrared spectrum from full quantummechanical calculations, submitted January, 2021, 2021;

[97] Boudon V, Pierre G, Bürger H. High-Resolution Spectroscopy and Analysis of the v4 Bending Region of SF6 near 615 cm-1, Journal of Molecular Spectroscopy 2001; 205: 304-11.

[98] Faye M, Boudon V, Loëte M, Roy P, Manceron L. Observation and analysis of the SF6 $v 2+v 4-v 5$ band: Improved parameters for the $v 5=1$ state, Journal of Molecular 
Spectroscopy 2016; 325: 35-41.

[99] Boudon V, Manceron L, Kwabia Tchana F, Loëte M, Lago L, Roy P. Resolving the forbidden band of SF6, Physical Chemistry Chemical Physics 2014; 16: 1415-23.

[100] Flaud J-M, Camy-Peyret C, Johns JWC. The far-infrared Spectrum of hydrogen sulfide. The (000) rotational constants of $\mathrm{H}_{2}{ }^{32} \mathrm{~S}, \mathrm{H}_{2}{ }^{33} \mathrm{~S}, \mathrm{H}_{2}{ }^{34} \mathrm{~S}$., Can. J. Phys. 1983; 61: 1462-73.

[101] Willemot E. Vibration-rotation Hamiltonian for asymmetric Cs molecules adapted to very strong Coriolis resonance: Application to the microwave reinvestigations of the $v 7$ and $v 9$ states of $\mathrm{H} 12 \mathrm{COOH}$ and D12COOH, Journal of Molecular Spectroscopy 1986; 120: $246-75$.

[102] Charo A, Lucia FCD. The Millimeter and Submillimeter Spectrum of $\mathrm{HO}_{2}$ : The Effects of Unpaired Electronic Spin in a Light Asymmetric Rotor, J. Mol. Spectrosc. 1982; 94: 426-36.

[103] Carten KP, Lovejoy RW. Modeling The Chlorine Nitrate $\mathrm{n}_{4}$ Vibration- Rotation Band, J. Quant. Spectrosc. Radiat. Transfer 1991; 46: 513-7.

[104] Esse Fv. The molecular structure of $\mathrm{NO}^{+}$, private communication, 1994.

[105] Cohen E. The molecular structure of hypobromous acid, private communication, 2002.

[106] Tan TL, Lau SY, Ong PP, Goh KL, Teo HH. High-Resolution Fourier Transform Infrared Spectrum of the $v 12$ Fundamental Band of Ethylene (C2H4), Journal of Molecular Spectroscopy 2000; 203: 310-3.

[107] De Vleeschouwer M, Lambeau C, Van Lerberghe D, Janssens E, Fayt A. Absorption spectroscopy of ethylene $\mathrm{H} 212 \mathrm{C} 13 \mathrm{CH} 2$ in the $4500-\mathrm{cm}-1$ region, Journal of Molecular Spectroscopy 1981; 90: 273-86.

[108] Georges R, Bach M, Herman M. The vibrational energy pattern in ethylene (12C2H4), Molecular Physics 1999; 97: 279-92.

[109] Duncan JL, McKean DC, Mallinson PD. Infrared crystal spectra of C2H4, C2D4, and as$\mathrm{C} 2 \mathrm{H} 2 \mathrm{D} 2$ and the general harmonic force field of ethylene, Journal of Molecular Spectroscopy 1973; 45: 221-46.

[110] Duncan JL, Ferguson AM, Goodlad ST. Local mode interpretation of the CH and CD stretching vibrational manifolds of isotopic ethylenes, C2H3D and C2HD3, Spectrochimica Acta Part A: Molecular Spectroscopy 1993; 49: 149-60.

[111] Herbin P, Blanquet G, Valentin A. Vibration-rotation analysis of C2H3D from 725 to $1170 \mathrm{~cm}-1$, Journal of Molecular Spectroscopy 1988; 127: 390-8.

[112] Viglaska-Aflalo D, Rey M, Nikitin A, Delahaye T. A global view of isotopic effects on ro-vibrational spectra of six-atomic molecules: a case study of eleven ethylene species, Physical Chemistry Chemical Physics 2020; 22: 3204-16.

[113] Rey M, Delahaye T, Nikitin AV, Tyuterev VG. First theoretical global line lists of ethylene $(12 \mathrm{C} 2 \mathrm{H} 4)$ spectra for the temperature range $50-700 \mathrm{~K}$ in the far-infrared for quantification of absorption and emission in planetary atmospheres $\star$, A\&A 2016; 594:

[114] Virtual Planetary Laboratory of the University of Washington, Methanol $\left(\mathrm{CH}_{3} \mathrm{OH}\right) .2016$, Available from: http://vpl.astro.washington.edu/spectra/methanol.htm.

[115] De Lucia FC, Herbst E, Anderson T, Helminger P. The analysis of the rotational spectrum of methanol to microwave accuracy, Journal of Molecular Spectroscopy 1989; 134: 395-411.

[116] Anderson DR, Overend J. The $v 3$ band of $\mathrm{CH} 3 \mathrm{Br}$ at high resolution, Spectrochimica Acta Part A: Molecular Spectroscopy 1971; 27: 2013-5.

[117] Betrencourt M, Morillon-Chapey M, Blanquet G, Walrand. J. Diode Laser Spectroscopy 
of Methyl Chloride Near $14 \mathrm{~mm}$ toward Its Detection in the Stratosphere, J. Mol. Spectrosc. 1988; 128: 433-43.

[118] Betrencourt-Stirnemann C, Graner G. High Resolution Infrared Spectrum of $\mathrm{CH}_{3} \mathrm{Br}$ : The $v_{4}$ Band Near $3100 \mathrm{~cm}^{-1}$, J. Mol. Spectrosc. 1974; 51: 216-37.

[119] Deroche J-C, Betrencourt-Stirnemann C. Rotational analysis of $\mathrm{CH}_{3} \mathrm{Br} v_{6}$ perpendicular band through far infra-red laser lines, Mol. Phys. 1976; 32: 921-30.

[120] Šimečková M, Urban Š, Fuchs U, Lewen F, Winnewisser G, Morino I, Yamada KMT. Ground state spectrum of methylcyanide, Journal of Molecular Spectroscopy 2004; 226: 123-36.

[121] Boucher D, Burie J, Bauer A, Dubrulle A, Demaison J. Microwave spectra of molecules of astrophysical interest. XIX. methyl cyanide, Journal of Physical and Chemical Reference Data 1980; 9: 659-720.

[122] Duncan JL, McKean DC, Tullini F, Nivellini GD, Perez Peña J. Methyl cianide: Spectroscopic studies of isotopically substituted species, and the harmonic potential function, Journal of Molecular Spectroscopy 1978; 69: 123-40.

[123] Koivusaari M, Horneman VM, Anttila R. High-resolution study of the infrared band $v 8$ of CH3CN, Journal of Molecular Spectroscopy 1992; 152: 377-88.

[124] Tolonen AM, Koivusaari M, Paso R, Schroderus J, Alanko S, Anttila R. The Infrared Spectrum of Methyl Cyanide Between 850 and $1150 \mathrm{~cm}-1$ : Analysis of the v4, v7, and 3v18 Bands with Resonances, Journal of Molecular Spectroscopy 1993; 160: 554-65.

[125] Paso R, Anttila R, Koivusaari M. The Infrared Spectrum of Methyl Cyanide Between 1240 and $1650 \mathrm{~cm}-1$ : The Coupled Band System $v 3, v \pm 16$, and $v 7+v \pm 28$, Journal of Molecular Spectroscopy 1994; 165: 470-80.

[126] Carlos M, Gruson O, Richard C, Boudon V, Rotger M, Thomas X, Maul C, Sydow C, Domanskaya A, Georges R, Soulard P, Pirali O, Goubet M, Asselin P, Huet TR. Highresolution spectroscopy and global analysis of CF4 rovibrational bands to model its atmospheric absorption, Journal of Quantitative Spectroscopy and Radiative Transfer 2017; 201: 75-93.

[127] Arié E, Johns JWC. The Bending Energy Levels of $\mathrm{C}_{4} \mathrm{H}_{2}$, J. Mol. Spectrosc. 1992; 155: 195-204.

[128] Koops T, Visser T, Smit WMA. The harmonic force field and absolute infrared intensities of diacetylene, Journal of Molecular Structure 1984; 125: 179-96.

[129] Dang-Nhu M, Guelachvili G, Ramsay DA. Absolute line intensities of the 5- $\mu \mathrm{m} v 5-$ fundamental band of diacetylene, Journal of Molecular Spectroscopy 1991; 146: 513-5.

[130] N. Jacquinet-Husson EA, J. Ballard, A. Barbe, G. Bjoraker, B. Bonnet, L. R. Brown, C. Camy-Peyret, J.P. Champion, A. Chédin, A. Chursin, C. C1erbaux, G. Duxbury, J.-M. Flaud, N. Fourrié, A. Fayt, G. Graner, R. Gamache, A. Goldman, Vl. Golovko, G. Guelachvili, J.-M. Hartmann, J. C. Hilico, J Hillman, G. Lefèvre, E. Lellouch, S.N. Mikhailenko, O.V.. Naumenko, V. Nemtchinov, D.A. Newnham, A. Nikitin, J. Orphal, A. Perrin, D.C. Reuter, C.P. Rinsland, L. Rosenmann, L.S. Rothman, N. A. Scott, J. Selby, L.N. Sinitsa, J.M. Sirota, A. M. Smith, K.M. Smith, Vl. G. Tyuterev, R. H. Tipping, S. Urban , P. Varanasi, M. Weber. The 1997 spectroscopic GEISA databank, J. Quant. Spectrosc. Radiat. Transfer 1999; 62: 205-54.

[131] Guelachvili G, Craig AM, Ramsay DA. High-Resolution Fourier Studies of Diacetylene in the Regions of the $v_{4}$ and $v_{5}$ Fundamentals, J. Mol. Spectrosc. 1984; 105: 156-92.

[132] Khlifi M, Paillous P, Delpech C, Nishio M, Bruston P, Raulin F. Absolute IR Band 
Intensities of Diacetylene in the 250-4300 cm-1 Region: Implications for Titan' $\mathrm{s}$ Atmosphere, Journal of Molecular Spectroscopy 1995; 174: 116-22.

[133] Shimanouchi T. Tables of Molecular Vibrational Frequencies Consolidated Volume I, National Standards Reference Data Serial 1972; 39: 1-161.

[134] Lafferty WJ, Lovas FJ. Microwave Spectra of Molecules of Astrophysical Interest. XIII. Cyanoacetylene, J. Phys. Chem. Ref. Data 1978; 7: 441-93.

[135] Uyemura M, Deguchi S, Nakada Y, Onaka T. Infrared Intensities of Bending Fundamentals in Gaseous HCCCN and DCCCN, Bull. Chem. Soc. Japan 1982; 55: 3848.

[136] Uyemura M, Maeda S. The Infrared Intensities of Stretching Fundamentals in Gaseous and Crystalline Cyanoacetylene, Bull. Chem. Soc. Japan 1974; 47: 2930-5.

[137] Deguchi S, Nakada Y, Onaka T, Uyemura M. Vibrational Excitation of Cyanoacetylene, Publications of the Astronomical Society of Japan 1979; 31: 105-13.

[138] Arie E, Dang Nhu M, Arcas P, Graner G, Bürger H, Pawelke G, Khlifi M, Raulin F. Analysis of cyanoacetylene spectra in the mid-infrared, Journal of Molecular Spectroscopy 1990; 143: 318-26.

[139] Khlifi M, Raulin F, Dang-Nhu M. Integrated band intensity versus temperature for the $v 1$, $v 2, v 5$, and $v 6$ bands of cyanoacetylene, Journal of Molecular Spectroscopy 1992; 155: 77-83.

[140] Winther F, Klee S, Mellau G, Naïm S, Mbosei L, Fayt A. The $v_{1}$ Band System of H-CCCN (Cyanoacetylene), J. Mol. Spectrosc. 1996; 175: 354-62.

[141] Piszczatowski K, Łach G, Przybytek M, Komasa J, Pachucki K, Jeziorski B. Theoretical Determination of the Dissociation Energy of Molecular Hydrogen, J. Chem. Theory Comput. 2009; 5: 3039-48.

[142] Pachucki K, Komasa J. Rovibrational levels of HD, Phys. Chem. Chem. Phys. 2010; 12: 9188-96.

[143] Burkholder JB, Lovejoy ER, Hammer PD, Howard CJ. High-Resolution Fourier Transform Infrared Spectra of ${ }^{12} \mathrm{C}^{32} \mathrm{~S},{ }^{12} \mathrm{C}^{33} \mathrm{~S},{ }^{12} \mathrm{C}^{34} \mathrm{~S}$, and ${ }^{13} \mathrm{C}^{32} \mathrm{~S}$, J. Mol. Spectrosc. 1987; 124: 450-7.

[144] Underwood DS, Yurchenko SN, Tennyson J, Al-Refaie AF, Clausen S, Fateev A. ExoMol molecular line lists - XVII. The rotation-vibration spectrum of hot $\mathrm{SO}_{3}$, Monthly Notices of the Royal Astronomical Society 2016; 462: 4300-13.

[145] Maki A, Blake TA, Sams RL, Vulpanovici N, Barber J, Chrysostom ETH, Masiello T, Nibler JW, Weber A. High-Resolution Infrared Spectra of the $v_{2}, v_{3}, v_{4}$, and $2 v_{3}$ Bands of ${ }^{32} \mathrm{~S}^{16} \mathrm{O}_{3}$, Journal of Molecular Spectroscopy 2001; 210: 240-9.

[146] Maki AG. High-Resolution Infrared Spectra of Cyanogen and Cyanogen- ${ }^{15} \mathrm{~N}^{2}$, J. Chem. Phys. 1965; 43: 3193-9.

[147] Grecu JC, Winnewisser BP, Winnewisser M. HIgh-Resolution Fourier Transform Infrared Spectrum of the $v_{5}$ Fundamental Band of Cyanogen, NCCN, J. Mol. Spectrosc. 1993; 159: 534-50.

[148] Tchana FK, Lafferty WJ, Flaud JM, Manceron L, Ndao M. High-resolution analysis of the $v_{1}$ and $v_{5}$ bands of phosgene ${ }^{35} \mathrm{C}^{12} \mathrm{CO}$ and ${ }^{35} \mathrm{Cl}^{37} \mathrm{ClCO}$, Molecular Physics 2015; 113: 3241-6.

[149] Papoušek D, Pracna P, Winnewisser M, Klee S, Demaison J. Simultaneous Rovibrational Analysis of the v2, v3, v5, and v6 Bands of H312CF, Journal of Molecular Spectroscopy 1999; 196: 319-23. 
[150] Richard C, Boudon V, Rizopoulos A, Vander Auwera J, Kwabia Tchana F. Line positions and intensities for the $v 2 / v 4$ bands of 5 isotopologues of germane near $11.5 \mu \mathrm{m}$, Journal of Quantitative Spectroscopy and Radiative Transfer 2021; 260: 107474.

[151] Boudon V, Grigoryan T, Philipot F, Richard C, Tchana FK, Manceron L, Rizopoulos A, Auwera JV, Encrenaz T. Line positions and intensities for the $v 3$ band of 5 isotopologues of germane for planetary applications, Journal of Quantitative Spectroscopy and Radiative Transfer 2018; 205: 174-83.

[152] Nikitin AV, Rey M, Rodina A, Krishna BM, Tyuterev VG. Full-Dimensional Potential Energy and Dipole Moment Surfaces of GeH4 Molecule and Accurate First-Principle Rotationally Resolved Intensity Predictions in the Infrared, The Journal of Physical Chemistry A 2016; 120: 8983-97.

[153] Karlovets EV, Gordon IE, Hashemi R, Kochanov RV, Hargreaves RJ, Rothman LS. Addition of the line list for carbon disulfide to the HITRAN database: line positions, intensities, and half-widths of the $12 \mathrm{C} 32 \mathrm{~S} 2,32 \mathrm{~S} 12 \mathrm{C} 34 \mathrm{~S}, 32 \mathrm{~S} 12 \mathrm{C} 33 \mathrm{~S}$, and $13 \mathrm{C} 32 \mathrm{~S} 2$ isotopologues, Journal of Quantitative Spectroscopy and Radiative Transfer 2021; 258: 107275.

[154] Perrin A, Haykal I, KwabiaTchana F, Manceron L, Doizi D, Ducros G. New analysis of the $v 6$ and $2 v 3$ bands of methyl iodide (CH3I), Journal of Molecular Spectroscopy 2016; 324: 28-35.

[155] Alanko S. A Detailed Analysis of the $v 2 / v 5 / v 3+v 6$ Band System of13CH3I and12CH3I, Journal of Molecular Spectroscopy 1996; 177: 263-79.

[156] Egorov O, Nikitin A, Rey M, Rodina A, Tashkun S, Tyuterev V. Global modeling of NF3 line positions and intensities from far to mid-infrared up to $2200 \mathrm{~cm}-1$, Journal of Quantitative Spectroscopy and Radiative Transfer 2019; 239: 106668.

[157] Rey M, Nikitin AV, Tyuterev VG. Ab initio ro-vibrational Hamiltonian in irreducible tensor formalism: a method for computing energy levels from potential energy surfaces for symmetric-top molecules, Molecular Physics 2010; 108: 2121-35.

[158] Hmimou S, Msahal H, Najib H. First high-resolution FTIR study of the v1 = v4 = 1 rovibrational state of 14NF3 near $1523 \mathrm{~cm}-1$, Molecular Physics 2010; 108: 787-94.

[159] Cazzoli G, Puzzarini C. Lamb-dip spectrum of methylacetylene and methyldiacetylene: precise rotational transition frequencies and parameters of the main isotopic species, Astron. Astrophys. 2008; 487: 1197-202.

[160] Pracna P. Vibrational fundamentals for $\mathrm{C}_{3} \mathrm{H}_{4}$, private communication, J. Heyrovský Institute of Physical Chemistry, Academy of Sciences of the Czech Republic, 18223 Prague 8, Czech Republic, 2010.

[161] Yamada C, Hirota E, Kawaguchi K. Diode laser study of the $v_{2}$ band of the methyl radical, J. Chem. Phys. 1981; 75: 5256-64.

[162] Zahedi M, Harrison JA, Nibler JW. $266 \mathrm{~nm} \mathrm{CH}_{3} \mathrm{I}$ photodissociation: $\mathrm{CH}_{3}$ spectra and population distributions by coherent Raman spectroscopy, J. Chem. Phys. 1994; 100: 4043-55.

[163] Davis S, Anderson DT, Duxbury G, Nesbitt DJ. Jet-cooled molecular radicals in slit supersonic discharges: Sub-Doppler infrared studies of methyl radical, J. Chem. Phys. 1997; 107: 5661-75.

[164] Jacox ME. Vibrational and Electronic Energy Levels of Polyatomic Transient Molecules, American Chemical Society, New York, 1994. 
Figure

1 The $Q(T)$ determined by a direct sum, Eq. (2), over ab initio term values (red dashed curve), $Q(T)$ determined by the double product approximation Eq. (6) (blue curve with + symbols) and $Q(T)$ determined by the product approximation Eq. (5) (black dot-dashed curve) for ${ }^{12} \mathrm{C}^{16} \mathrm{O}_{2}$ versus temperature in $\mathrm{K}$.

$2 \quad Q(T)$ for ${ }^{18} \mathrm{OH}$ determined by direct summation of Eq. (2) versus the term value in wavenumbers for $T$ values: $500,1000,2000,3000,4000$, and $5000 \mathrm{~K}$. The saw tooth structure at low term value is due to the structure of the energy; groups of 4 near identical term values for the ${ }^{2} \Pi_{3 / 2} \pm$ states for the states with $F=J \pm 0$.

$3 Q(T)$ for ${ }^{18} \mathrm{OH}$ determined by direct summation of Eq. (2) versus the term value in wavenumbers for $T$ values: 500, 1000, 2000, 3000, 4000, and $5000 \mathrm{~K}$.

$4 Q_{\text {rot }}(T)$ for ${ }^{35} \mathrm{Cl}^{16} \mathrm{O}$ by direct summation of Eq. (2) versus the term value in wavenumbers for $T$ values: $500,1000,2000,3000,4000$, and $5000 \mathrm{~K}$.

Tables 
1 Molecule number, chemical formula, isotopologue number (ISO\#), AFGL code, state independent degeneracy factor $\left(g_{i}\right), Q(296 \mathrm{~K})$, and $T_{\max }$ in $\mathrm{K}$. 


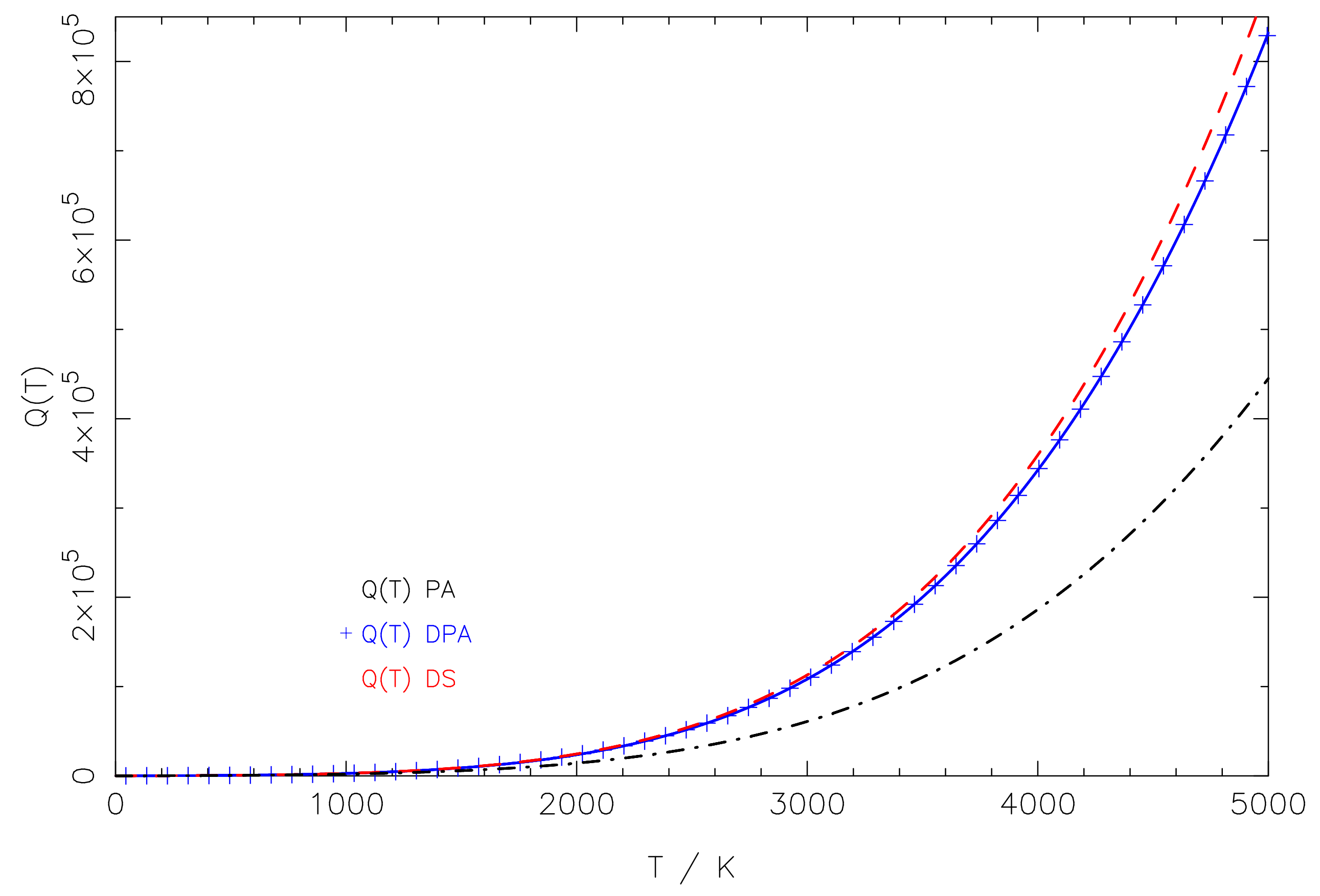




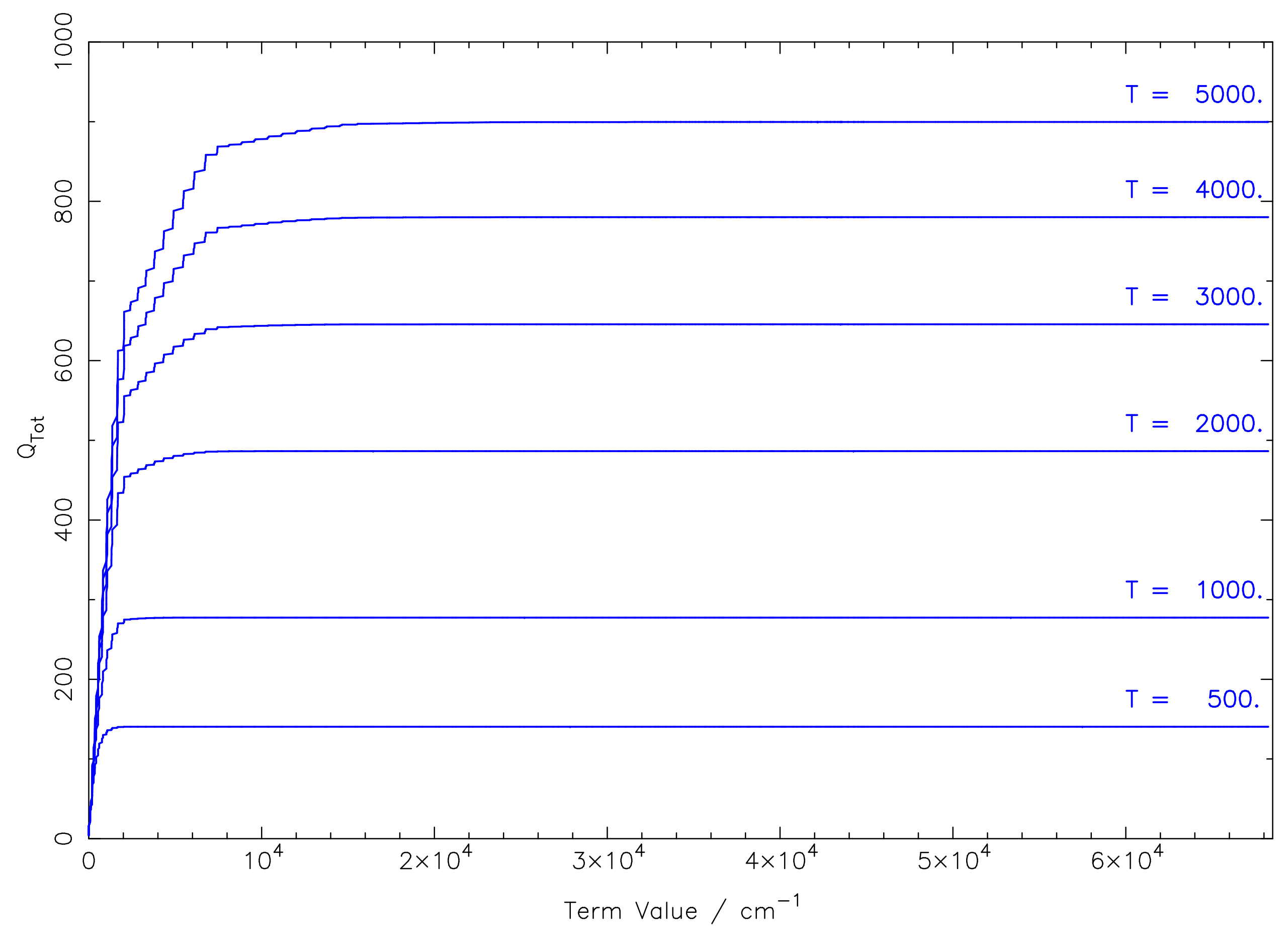




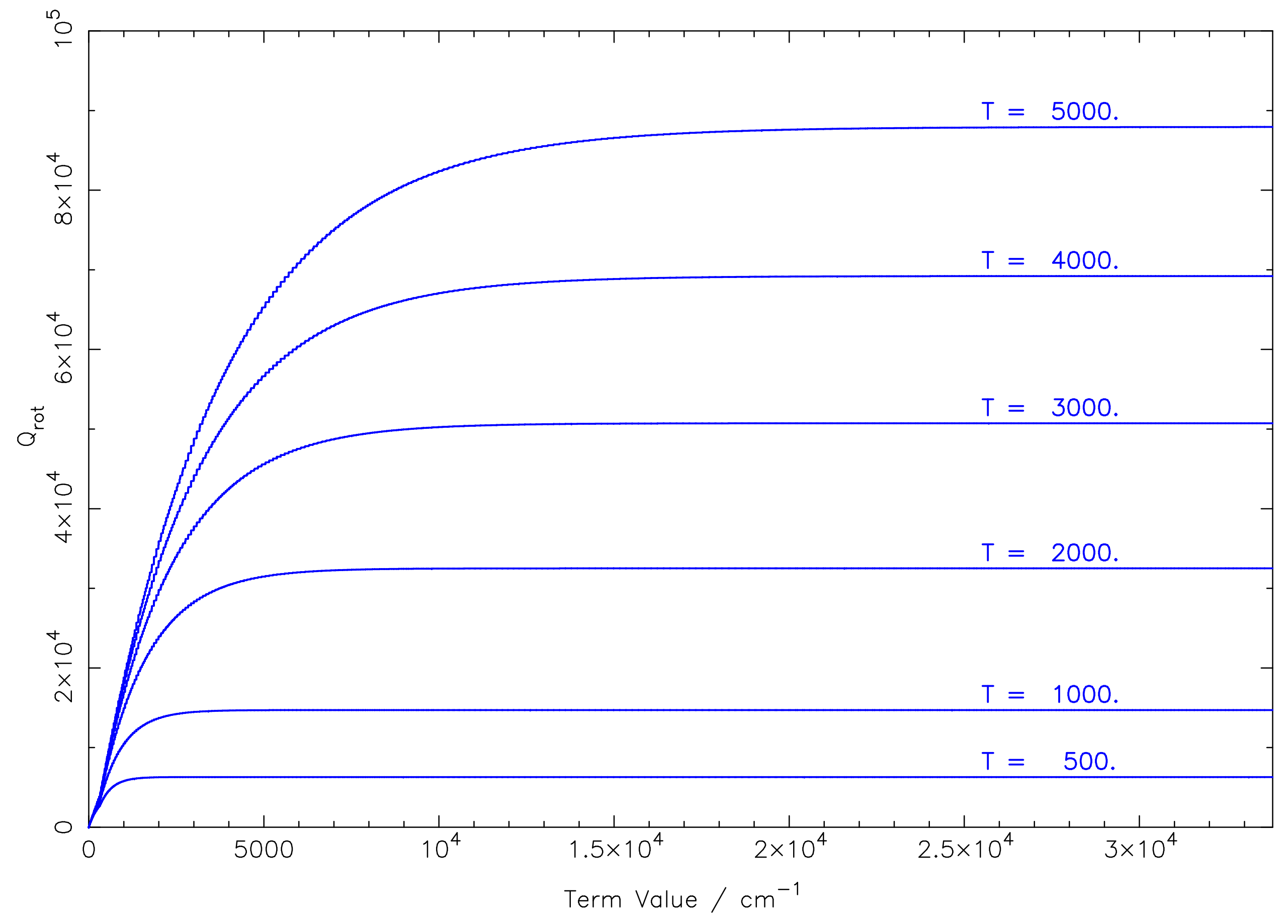


Click here to access/download;Figure;Figure_4.eps $\underline{\underline{\Perp}}$

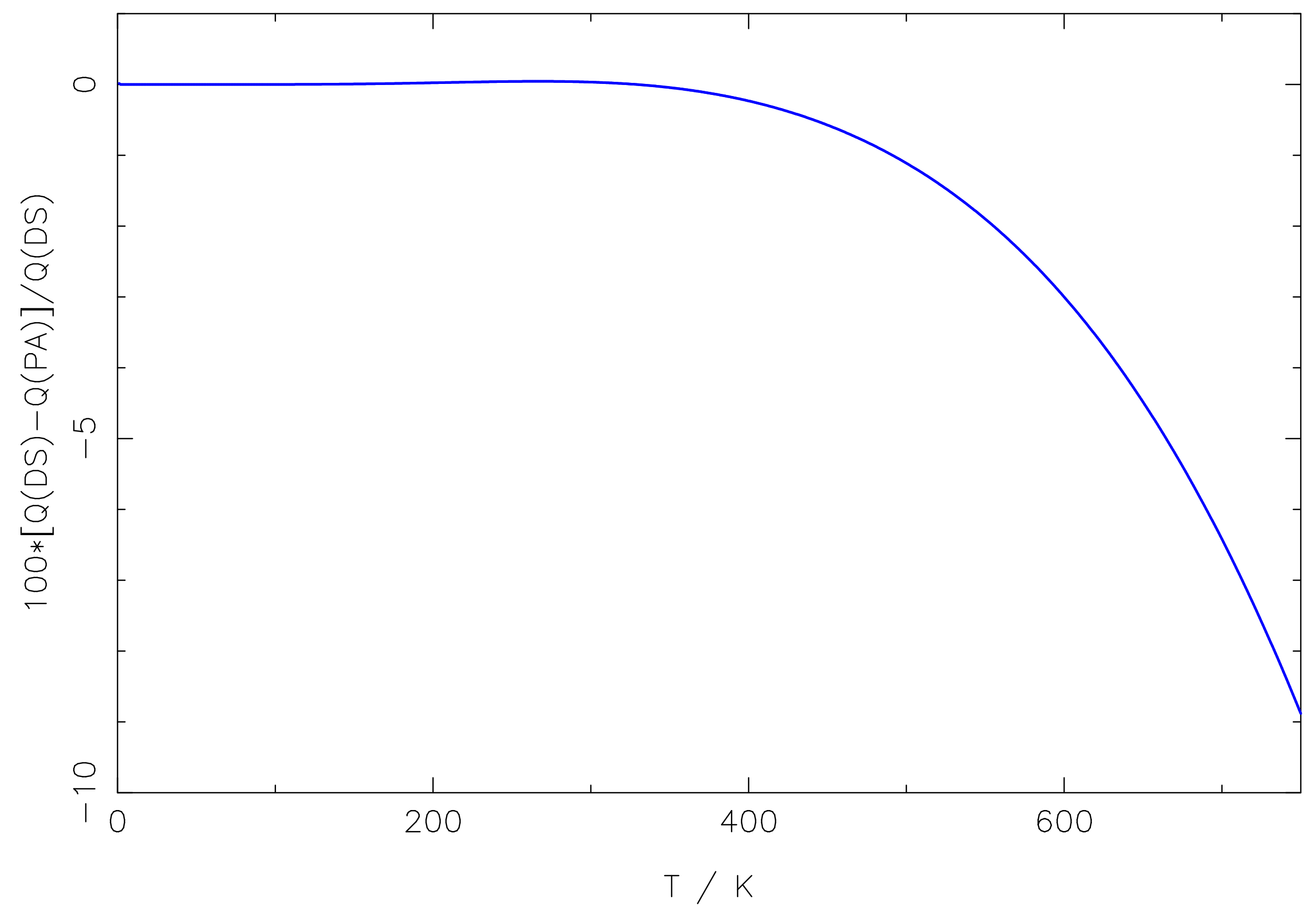


Table 1 Molecule number, chemical formula, isotopologue number (ISO\#), AFGL code, state independent degeneracy factor $\left(g_{i}\right), Q(296 \mathrm{~K})$, and $T_{\max }$ in K.

\begin{tabular}{|c|c|c|c|c|c|c|}
\hline $\begin{array}{c}\text { Molecule } \\
\#\end{array}$ & Formula & $\begin{array}{r}\mathrm{ISO} \\
\#\end{array}$ & $\begin{array}{r}\text { AFGL } \\
\text { code }\end{array}$ & $g_{i}$ & $Q(296 K)$ & $T_{\max } \mathrm{K}$ \\
\hline \multirow[t]{9}{*}{1} & $\mathrm{H}_{2}{ }^{16} \mathrm{O}$ & 1 & 161 & 1 & $1.7458 \times 10^{2}$ & 5000 \\
\hline & $\mathrm{H}_{2}{ }^{18} \mathrm{O}$ & 2 & 181 & 1 & $1.7605 \times 10^{2}$ & 5000 \\
\hline & $\mathrm{H}_{2}{ }^{17} \mathrm{O}$ & 3 & 171 & 6 & $1.0521 \times 10^{3}$ & 5000 \\
\hline & $\mathrm{HD}^{16} \mathrm{O}$ & 4 & 162 & 6 & $8.6474 \times 10^{2}$ & 5000 \\
\hline & $\mathrm{HD}^{18} \mathrm{O}$ & 5 & 182 & 6 & $8.7557 \times 10^{2}$ & 5000 \\
\hline & $\mathrm{HD}^{17} \mathrm{O}$ & 6 & 172 & 36 & $5.2268 \times 10^{3}$ & 5000 \\
\hline & $\mathrm{D}_{2}{ }^{16} \mathrm{O}$ & 7 & 262 & 1 & $1.0278 \times 10^{3}$ & 6000 \\
\hline & $\mathrm{D}_{2}{ }^{18} \mathrm{O}$ & 8 & 282 & 1 & $1.0434 \times 10^{3}$ & 6000 \\
\hline & $\mathrm{D}_{2}{ }^{17} \mathrm{O}$ & 9 & 272 & 6 & $6.2160 \times 10^{3}$ & 6000 \\
\hline \multirow[t]{13}{*}{2} & ${ }^{12} \mathrm{C}^{16} \mathrm{O}_{2}$ & 1 & 626 & 1 & $2.8609 \times 10^{2}$ & 5000 \\
\hline & ${ }^{13} \mathrm{C}^{16} \mathrm{O}_{2}$ & 2 & 636 & 2 & $5.7664 \times 10^{2}$ & 5000 \\
\hline & ${ }^{16} \mathrm{O}^{12} \mathrm{C}^{18} \mathrm{O}$ & 3 & 628 & 1 & $6.0781 \times 10^{2}$ & 3500 \\
\hline & ${ }^{16} \mathrm{O}^{12} \mathrm{C}^{17} \mathrm{O}$ & 4 & 627 & 6 & $3.5426 \times 10^{3}$ & 3500 \\
\hline & ${ }^{16} \mathrm{O}^{13} \mathrm{C}^{18} \mathrm{O}$ & 5 & 638 & 2 & $1.2255 \times 10^{3}$ & 3500 \\
\hline & ${ }^{16} \mathrm{O}^{13} \mathrm{C}^{17} \mathrm{O}$ & 6 & 637 & 12 & $7.1413 \times 10^{3}$ & 3500 \\
\hline & ${ }^{12} \mathrm{C}^{18} \mathrm{O}_{2}$ & 7 & 828 & 1 & $3.2342 \times 10^{2}$ & 5000 \\
\hline & ${ }^{17} \mathrm{O}^{12} \mathrm{C}^{18} \mathrm{O}$ & 8 & 827 & 6 & $3.7666 \times 10^{3}$ & 3500 \\
\hline & ${ }^{12} \mathrm{C}^{17} \mathrm{O}_{2}$ & 9 & 727 & 1 & $1.0972 \times 10^{4}$ & 5000 \\
\hline & ${ }^{13} \mathrm{C}^{18} \mathrm{O}_{2}$ & 0 & 838 & 2 & $6.5224 \times 10^{2}$ & 5000 \\
\hline & ${ }^{18} \mathrm{O}^{13} \mathrm{C}^{17} \mathrm{O}$ & 11 & 837 & 12 & $7.5950 \times 10^{3}$ & 3500 \\
\hline & ${ }^{13} \mathrm{C}^{17} \mathrm{O}_{2}$ & 12 & 737 & 2 & $2.2120 \times 10^{4}$ & 5000 \\
\hline & ${ }^{14} \mathrm{C}^{16} \mathrm{O}_{2}$ & 13 & 646 & 1 & $2.9048 \times 10^{2}$ & 5000 \\
\hline \multirow[t]{18}{*}{3} & ${ }^{16} \mathrm{O}_{3}$ & 1 & 666 & 1 & $3.4750 \times 10^{3}$ & 1000 \\
\hline & ${ }^{16} \mathrm{O}^{16} \mathrm{O}^{18} \mathrm{O}$ & 2 & 668 & 1 & $7.5846 \times 10^{3}$ & 1000 \\
\hline & ${ }^{16} \mathrm{O}^{18} \mathrm{O}^{16} \mathrm{O}$ & 3 & 686 & 1 & $3.7030 \times 10^{3}$ & 1000 \\
\hline & ${ }^{16} \mathrm{O}^{16} \mathrm{O}^{17} \mathrm{O}$ & 4 & 667 & 6 & $4.4044 \times 10^{4}$ & 1000 \\
\hline & ${ }^{16} \mathrm{O}^{17} \mathrm{O}^{16} \mathrm{O}$ & 5 & 676 & 6 & $2.1742 \times 10^{4}$ & 1000 \\
\hline & ${ }^{18} \mathrm{O}^{18} \mathrm{O}^{16} \mathrm{O}$ & 6 & 886 & 1 & $7.9376 \times 10^{3}$ & 1000 \\
\hline & ${ }^{18} \mathrm{O}^{16} \mathrm{O}^{18} \mathrm{O}$ & 7 & 868 & 1 & $4.0703 \times 10^{3}$ & 1000 \\
\hline & ${ }^{16} \mathrm{O}^{17} \mathrm{O}^{18} \mathrm{O}$ & 8 & 678 & 6 & $4.6563 \times 10^{4}$ & 1000 \\
\hline & ${ }^{17} \mathrm{O}^{16} \mathrm{O}^{18} \mathrm{O}$ & 9 & 768 & 6 & $4.7135 \times 10^{4}$ & 1000 \\
\hline & ${ }^{17} \mathrm{O}^{18} \mathrm{O}^{16} \mathrm{O}$ & 10 & 786 & 6 & $4.6074 \times 10^{4}$ & 1000 \\
\hline & ${ }^{17} \mathrm{O}^{17} \mathrm{O}^{16} \mathrm{O}$ & 11 & 776 & 36 & $2.7051 \times 10^{5}$ & 1000 \\
\hline & ${ }^{17} \mathrm{O}^{16} \mathrm{O}^{17} \mathrm{O}$ & 12 & 767 & 1 & $1.3704 \times 10^{5}$ & 1000 \\
\hline & ${ }^{18} \mathrm{O}_{3}$ & 13 & 888 & 1 & $4.2647 \times 10^{3}$ & 1000 \\
\hline & ${ }^{18} \mathrm{O}^{18} \mathrm{O}^{17} \mathrm{O}$ & 14 & 887 & 6 & $4.9325 \times 10^{4}$ & 1000 \\
\hline & ${ }^{18} \mathrm{O}^{17} \mathrm{O}^{18} \mathrm{O}$ & 15 & 878 & 6 & $2.5005 \times 10^{4}$ & 1000 \\
\hline & ${ }^{17} \mathrm{O}^{17} \mathrm{O}^{18} \mathrm{O}$ & 16 & 778 & 36 & $2.8147 \times 10^{5}$ & 1000 \\
\hline & ${ }^{17} \mathrm{O}^{18} \mathrm{O}^{17} \mathrm{O}$ & 17 & 787 & 1 & $1.4342 \times 10^{5}$ & 1000 \\
\hline & ${ }^{17} \mathrm{O}_{3}$ & 18 & 777 & 6 & $8.4189 \times 10^{5}$ & 1000 \\
\hline
\end{tabular}




\begin{tabular}{|c|c|c|c|c|c|c|}
\hline \multirow[t]{5}{*}{4} & ${ }^{14} \mathrm{~N}_{2}{ }^{16} \mathrm{O}$ & 1 & 446 & 9 & $4.9849 \times 10^{3}$ & 5000 \\
\hline & ${ }^{14} \mathrm{~N}^{15} \mathrm{~N}^{16} \mathrm{O}$ & 2 & 456 & 6 & $3.3616 \times 10^{3}$ & 5000 \\
\hline & ${ }^{15} \mathrm{~N}^{14} \mathrm{~N}^{16} \mathrm{O}$ & 3 & 546 & 6 & $3.4580 \times 10^{3}$ & 5000 \\
\hline & ${ }^{14} \mathrm{~N}_{2}{ }^{18} \mathrm{O}$ & 4 & 448 & 9 & $5.3135 \times 10^{3}$ & 5000 \\
\hline & ${ }^{14} \mathrm{~N}_{2}{ }^{17} \mathrm{O}$ & 5 & 447 & 54 & $3.0966 \times 10^{4}$ & 5000 \\
\hline \multirow[t]{9}{*}{5} & ${ }^{12} \mathrm{C}^{16} \mathrm{O}$ & 1 & 26 & 1 & $1.0742 \times 10^{2}$ & 9000 \\
\hline & ${ }^{13} \mathrm{C}^{16} \mathrm{O}$ & 2 & 36 & 2 & $2.2469 \times 10^{2}$ & 9000 \\
\hline & ${ }^{12} \mathrm{C}^{18} \mathrm{O}$ & 3 & 28 & 1 & $1.1277 \times 10^{2}$ & 9000 \\
\hline & ${ }^{12} \mathrm{C}^{17} \mathrm{O}$ & 4 & 27 & 6 & $6.6117 \times 10^{2}$ & 9000 \\
\hline & ${ }^{13} \mathrm{C}^{18} \mathrm{O}$ & 5 & 38 & 2 & $2.3644 \times 10^{2}$ & 9000 \\
\hline & ${ }^{13} \mathrm{C}^{17} \mathrm{O}$ & 6 & 37 & 12 & $1.3847 \times 10^{3}$ & 9000 \\
\hline & ${ }^{14} \mathrm{C}^{16} \mathrm{O}$ & 7 & 46 & 1 & $1.1693 \times 10^{2}$ & 9000 \\
\hline & ${ }^{14} \mathrm{C}^{18} \mathrm{O}$ & 8 & 48 & 1 & $1.2331 \times 10^{2}$ & 9000 \\
\hline & ${ }^{14} \mathrm{C}^{17} \mathrm{O}$ & 9 & 47 & 6 & $7.2137 \times 10^{2}$ & 9000 \\
\hline \multirow[t]{4}{*}{6} & ${ }^{12} \mathrm{CH}_{4}$ & 1 & 211 & 1 & $5.9053 \times 10^{2}$ & 2500 \\
\hline & ${ }^{13} \mathrm{CH}_{4}$ & 2 & 311 & 2 & $1.1811 \times 10^{3}$ & 2500 \\
\hline & ${ }^{12} \mathrm{CH}_{3} \mathrm{D}$ & 3 & 212 & 3 & $4.7947 \times 10^{3}$ & 2500 \\
\hline & ${ }^{13} \mathrm{CH}_{3} \mathrm{D}$ & 4 & 312 & 6 & $9.6010 \times 10^{3}$ & 2500 \\
\hline \multirow[t]{6}{*}{7} & ${ }^{16} \mathrm{O}_{2}$ & 1 & 66 & 1 & $2.1573 \times 10^{2}$ & 7500 \\
\hline & ${ }^{16} \mathrm{O}^{18} \mathrm{O}$ & 2 & 68 & 1 & $4.5523 \times 10^{2}$ & 7500 \\
\hline & ${ }^{16} \mathrm{O}^{17} \mathrm{O}$ & 3 & 67 & 6 & $2.6581 \times 10^{3}$ & 7500 \\
\hline & ${ }^{18} \mathrm{O}^{18} \mathrm{O}$ & 4 & 88 & 1 & $2.4232 \times 10^{2}$ & 7500 \\
\hline & ${ }^{18} \mathrm{O}^{17} \mathrm{O}$ & 5 & 87 & 6 & $2.8191 \times 10^{3}$ & 7500 \\
\hline & ${ }^{17} \mathrm{O}^{17} \mathrm{O}$ & 6 & 77 & 1 & $8.2238 \times 10^{3}$ & 7500 \\
\hline \multirow[t]{3}{*}{8} & ${ }^{14} \mathrm{~N}^{16} \mathrm{O}$ & 1 & 46 & 3 & $1.1411 \times 10^{3}$ & 5000 \\
\hline & ${ }^{15} \mathrm{~N}^{16} \mathrm{O}$ & 2 & 56 & 2 & $7.8831 \times 10^{2}$ & 5000 \\
\hline & ${ }^{14} \mathrm{~N}^{18} \mathrm{O}$ & 3 & 48 & 3 & $1.1825 \times 10^{3}$ & 5000 \\
\hline \multirow[t]{4}{*}{9} & ${ }^{32} \mathrm{~S}^{16} \mathrm{O}_{2}$ & 1 & 626 & 1 & $6.3391 \times 10^{3}$ & 5000 \\
\hline & ${ }^{34} \mathrm{~S}^{16} \mathrm{O}_{2}$ & 2 & 646 & 1 & $6.3678 \times 10^{3}$ & 5000 \\
\hline & ${ }^{33} \mathrm{~S}^{16} \mathrm{O}_{2}$ & 3 & 636 & 4 & $2.5607 \times 10^{4}$ & 5000 \\
\hline & ${ }^{16} \mathrm{O}^{32} \mathrm{~S}^{18} \mathrm{O}$ & 4 & 628 & 1 & $1.3681 \times 10^{4}$ & 5000 \\
\hline \multirow[t]{2}{*}{10} & ${ }^{14} \mathrm{~N}^{16} \mathrm{O}_{2}$ & 1 & 646 & 3 & $1.3575 \times 10^{4}$ & 1000 \\
\hline & ${ }^{15} \mathrm{~N}^{16} \mathrm{O}_{2}$ & 2 & 656 & 2 & $9.2929 \times 10^{3}$ & 1000 \\
\hline \multirow[t]{2}{*}{11} & ${ }^{14} \mathrm{NH}_{3}$ & 1 & 4111 & 3 & $1.7252 \times 10^{3}$ & 6000 \\
\hline & ${ }^{15} \mathrm{NH}_{3}$ & 2 & 5111 & 2 & $1.1533 \times 10^{3}$ & 6000 \\
\hline \multirow[t]{2}{*}{12} & $\mathrm{H}^{14} \mathrm{~N}^{16} \mathrm{O}_{3}$ & 1 & 146 & 6 & $2.1393 \times 10^{5}$ & 3500 \\
\hline & $\mathrm{H}^{15} \mathrm{~N}^{16} \mathrm{O}_{3}$ & 2 & 156 & 4 & $1.4313 \times 10^{5}$ & 3500 \\
\hline \multirow[t]{3}{*}{13} & ${ }^{16} \mathrm{OH}$ & 1 & 61 & 2 & $8.0348 \times 10^{1}$ & 9000 \\
\hline & ${ }^{18} \mathrm{OH}$ & 2 & 81 & 2 & $8.0881 \times 10^{1}$ & 5000 \\
\hline & ${ }^{16} \mathrm{OD}$ & 3 & 62 & 3 & $2.0931 \times 10^{2}$ & 5000 \\
\hline \multirow[t]{2}{*}{14} & $\mathrm{H}^{19} \mathrm{~F}$ & 1 & 19 & 4 & $4.1469 \times 10^{1}$ & 6000 \\
\hline & $\mathrm{D}^{19} \mathrm{~F}$ & 2 & 29 & 6 & $1.1591 \times 10^{2}$ & 6000 \\
\hline \multirow[t]{4}{*}{15} & $\mathrm{H}^{35} \mathrm{Cl}$ & 1 & 15 & 8 & $1.6065 \times 10^{2}$ & 6000 \\
\hline & $\mathrm{H}^{37} \mathrm{Cl}$ & 2 & 17 & 8 & $1.6089 \times 10^{2}$ & 6000 \\
\hline & $\mathrm{D}^{35} \mathrm{Cl}$ & 3 & 25 & 12 & $4.6278 \times 10^{2}$ & 6000 \\
\hline & $\mathrm{D}^{37} \mathrm{Cl}$ & 4 & 27 & 12 & $4.6413 \times 10^{2}$ & 6000 \\
\hline
\end{tabular}




\begin{tabular}{|c|c|c|c|c|c|c|}
\hline \multirow[t]{4}{*}{16} & $\mathrm{H}^{79} \mathrm{Br}$ & 1 & 19 & 8 & $2.0017 \times 10^{2}$ & 6000 \\
\hline & $\mathrm{H}^{81} \mathrm{Br}$ & 2 & 11 & 8 & $2.0023 \times 10^{2}$ & 6000 \\
\hline & $\mathrm{D}^{79} \mathrm{Br}$ & 3 & 29 & 12 & $5.8640 \times 10^{2}$ & 6000 \\
\hline & $\mathrm{D}^{81} \mathrm{Br}$ & 4 & 21 & 12 & $5.8676 \times 10^{2}$ & 6000 \\
\hline \multirow[t]{2}{*}{17} & $\mathrm{H}^{127} \mathrm{I}$ & 1 & 17 & 12 & $3.8899 \times 10^{2}$ & 6000 \\
\hline & $D^{127} I$ & 2 & 27 & 18 & $1.1471 \times 10^{3}$ & 6000 \\
\hline \multirow[t]{2}{*}{18} & ${ }^{35} \mathrm{Cl}^{16} \mathrm{O}$ & 1 & 56 & 4 & $3.2918 \times 10^{3}$ & 5000 \\
\hline & ${ }^{37} \mathrm{Cl}^{16} \mathrm{O}$ & 2 & 76 & 4 & $3.3492 \times 10^{3}$ & 5000 \\
\hline \multirow[t]{6}{*}{19} & ${ }^{16} \mathrm{O}^{12} \mathrm{C}^{32} \mathrm{~S}$ & 1 & 622 & 1 & $1.2207 \times 10^{3}$ & 5000 \\
\hline & ${ }^{16} \mathrm{O}^{12} \mathrm{C}^{34} \mathrm{~S}$ & 2 & 624 & 1 & $1.2531 \times 10^{3}$ & 5000 \\
\hline & ${ }^{16} \mathrm{O}^{13} \mathrm{C}^{32} \mathrm{~S}$ & 3 & 632 & 2 & $2.4835 \times 10^{3}$ & 5000 \\
\hline & ${ }^{16} \mathrm{O}^{12} \mathrm{C}^{33} \mathrm{~S}$ & 4 & 623 & 4 & $4.9487 \times 10^{3}$ & 5000 \\
\hline & ${ }^{18} \mathrm{O}^{12} \mathrm{C}^{32} \mathrm{~S}$ & 5 & 822 & 1 & $1.3134 \times 10^{3}$ & 5000 \\
\hline & ${ }^{16} \mathrm{O}^{13} \mathrm{C}^{34} \mathrm{~S}$ & 6 & 634 & 2 & $2.5465 \times 10^{3}$ & 5000 \\
\hline \multirow[t]{3}{*}{20} & $\mathrm{H}_{2}{ }^{12} \mathrm{C}^{16} \mathrm{O}$ & 1 & 126 & 1 & $2.8445 \times 10^{3}$ & 3500 \\
\hline & $\mathrm{H}_{2}{ }^{13} \mathrm{C}^{16} \mathrm{O}$ & 2 & 136 & 2 & $5.8368 \times 10^{3}$ & 5000 \\
\hline & $\mathrm{H}_{2}{ }^{12} \mathrm{C}^{18} \mathrm{O}$ & 3 & 128 & 1 & $2.9860 \times 10^{3}$ & 5000 \\
\hline \multirow[t]{2}{*}{21} & $\mathrm{H}^{16} \mathrm{O}^{35} \mathrm{Cl}$ & 1 & 165 & 8 & $1.9272 \times 10^{4}$ & 5000 \\
\hline & $\mathrm{H}^{16} \mathrm{O}^{37} \mathrm{Cl}$ & 2 & 167 & 8 & $1.9613 \times 10^{4}$ & 5000 \\
\hline \multirow[t]{3}{*}{22} & ${ }^{14} \mathrm{~N}_{2}$ & 1 & 44 & 1 & $4.6710 \times 10^{2}$ & 9000 \\
\hline & ${ }^{14} \mathrm{~N}^{15} \mathrm{~N}$ & 2 & 45 & 6 & $6.4410 \times 10^{2}$ & 9000 \\
\hline & ${ }^{15} \mathrm{~N}_{2}$ & 3 & 55 & 1 & $2.2230 \times 10^{2}$ & 9000 \\
\hline \multirow[t]{3}{*}{23} & $\mathrm{H}^{12} \mathrm{C}^{14} \mathrm{~N}$ & 1 & 124 & 6 & $8.9220 \times 10^{2}$ & 3500 \\
\hline & $\mathrm{H}^{13} \mathrm{C}^{14} \mathrm{~N}$ & 2 & 134 & 12 & $1.8310 \times 10^{3}$ & 3500 \\
\hline & $\mathrm{H}^{12} \mathrm{C}^{15} \mathrm{~N}$ & 3 & 125 & 4 & $6.1528 \times 10^{2}$ & 3500 \\
\hline \multirow[t]{2}{*}{24} & ${ }^{12} \mathrm{CH}_{3}{ }^{35} \mathrm{Cl}$ & 1 & 215 & 4 & $5.7915 \times 10^{4}$ & 5000 \\
\hline & ${ }^{12} \mathrm{CH}_{3}{ }^{37} \mathrm{Cl}$ & 2 & 217 & 4 & $5.8832 \times 10^{4}$ & 5000 \\
\hline 25 & $\mathrm{H}_{2}{ }^{16} \mathrm{O}_{2}$ & 1 & 1661 & 1 & $9.8480 \times 10^{3}$ & 6000 \\
\hline \multirow[t]{3}{*}{26} & ${ }^{12} \mathrm{C}_{2} \mathrm{H}_{2}$ & 1 & 1221 & 1 & $4.1245 \times 10^{2}$ & 5000 \\
\hline & $\mathrm{H}^{12} \mathrm{C}^{13} \mathrm{CH}$ & 2 & 1231 & 8 & $1.6557 \times 10^{3}$ & 5000 \\
\hline & $\mathrm{H}^{12} \mathrm{C}^{12} \mathrm{CD}$ & 3 & 1222 & 6 & $1.5937 \times 10^{3}$ & 5000 \\
\hline \multirow[t]{3}{*}{27} & ${ }^{12} \mathrm{C}_{2} \mathrm{H}_{6}$ & 1 & 1221 & 1 & $7.0873 \times 10^{4}$ & 5000 \\
\hline & ${ }^{12} \mathrm{CH}_{3}{ }^{13} \mathrm{CH}_{3}$ & 2 & 1231 & 2 & $3.6183 \times 10^{4}$ & 5000 \\
\hline & $\mathrm{H}_{3}{ }^{12} \mathrm{C}_{2} \mathrm{H}_{2} \mathrm{D}$ & 3 & 1222 & 12 & $3.9266 \times 10^{5}$ & 5000 \\
\hline 28 & ${ }^{31} \mathrm{PH}_{3}$ & 1 & 1111 & 2 & $3.2494 \times 10^{3}$ & 4500 \\
\hline \multirow[t]{2}{*}{29} & ${ }^{12} \mathrm{C}^{16} \mathrm{O}^{19} \mathrm{~F}_{2}$ & 1 & 269 & 1 & $7.0028 \times 10^{4}$ & 3500 \\
\hline & ${ }^{13} \mathrm{C}^{16} \mathrm{O}^{19} \mathrm{~F}_{2}$ & 2 & 369 & 2 & $1.4006 \times 10^{5}$ & 3500 \\
\hline 30 & ${ }^{32} \mathrm{~S}^{19} \mathrm{~F}_{6}$ & 1 & 29 & 1 & $1.6110 \times 10^{6}$ & 5000 \\
\hline \multirow[t]{3}{*}{31} & $\mathrm{H}_{2}{ }^{32} \mathrm{~S}$ & 1 & 121 & 1 & $5.0579 \times 10^{2}$ & 4000 \\
\hline & $\mathrm{H}_{2}{ }^{34} \mathrm{~S}$ & 2 & 141 & 1 & $5.0428 \times 10^{2}$ & 5000 \\
\hline & $\mathrm{H}_{2}{ }^{33} \mathrm{~S}$ & 3 & 131 & 4 & $2.0147 \times 10^{3}$ & 5000 \\
\hline 32 & $\mathrm{H}^{12} \mathrm{C}^{16} \mathrm{O}^{16} \mathrm{OH}$ & 1 & 126 & 4 & $3.9124 \times 10^{4}$ & 5000 \\
\hline 33 & $\mathrm{H}^{16} \mathrm{O}_{2}$ & 1 & 166 & 2 & $4.2998 \times 10^{3}$ & 5000 \\
\hline \multirow[t]{2}{*}{35} & ${ }^{35} \mathrm{Cl}^{16} \mathrm{O}^{14} \mathrm{~N}^{16} \mathrm{O}_{2}$ & 1 & 5646 & 12 & $4.7864 \times 10^{6}$ & 5000 \\
\hline & ${ }^{37} \mathrm{Cl}^{16} \mathrm{O}^{14} \mathrm{~N}^{16} \mathrm{O}_{2}$ & 2 & 7646 & 12 & $4.9082 \times 10^{6}$ & 5000 \\
\hline 36 & ${ }^{14} \mathrm{~N}^{16} \mathrm{O}^{+}$ & 1 & 46 & 3 & $3.1166 \times 10^{2}$ & 5000 \\
\hline
\end{tabular}




\begin{tabular}{|c|c|c|c|c|c|c|}
\hline \multirow[t]{2}{*}{37} & $\mathrm{H}^{16} \mathrm{O}^{79} \mathrm{Br}$ & 1 & 169 & 8 & $2.8335 \times 10^{4}$ & 5000 \\
\hline & $\mathrm{H}^{16} \mathrm{O}^{81} \mathrm{Br}$ & 2 & 161 & 8 & $2.8233 \times 10^{4}$ & 5000 \\
\hline \multirow[t]{3}{*}{38} & ${ }^{12} \mathrm{C}_{2} \mathrm{H}_{4}$ & 1 & 112211 & 1 & $1.1040 \times 10^{4}$ & 5000 \\
\hline & ${ }^{12} \mathrm{CH}_{2}{ }^{13} \mathrm{CH}_{2}$ & 2 & 112311 & 2 & $4.5189 \times 10^{4}$ & 5000 \\
\hline & ${ }^{12} \mathrm{CH}_{2}{ }^{13} \mathrm{CHD}$ & 3 & 112212 & 24 & $8.2452 \times 10^{4}$ & 5000 \\
\hline 39 & ${ }^{12} \mathrm{CH}_{3}{ }^{16} \mathrm{OH}$ & 1 & 2161 & 1 & $7.0570 \times 10^{4}$ & 3500 \\
\hline \multirow[t]{2}{*}{40} & ${ }^{12} \mathrm{CH}_{3}{ }^{79} \mathrm{Br}$ & 1 & 219 & 4 & $8.3049 \times 10^{4}$ & 5000 \\
\hline & ${ }^{12} \mathrm{CH}_{3}{ }^{81} \mathrm{Br}$ & 2 & 211 & 4 & $8.3392 \times 10^{4}$ & 5000 \\
\hline \multirow[t]{4}{*}{41} & ${ }^{12} \mathrm{CH}_{3}{ }^{12} \mathrm{C}^{14} \mathrm{~N}$ & 1 & 2124 & 3 & $8.8659 \times 10^{4}$ & 5000 \\
\hline & ${ }^{13} \mathrm{CH}_{3}{ }^{12} \mathrm{C}^{14} \mathrm{~N}$ & 2 & 3124 & 6 & $1.8363 \times 10^{5}$ & 5000 \\
\hline & ${ }^{12} \mathrm{CH}_{3}{ }^{13} \mathrm{C}^{14} \mathrm{~N}$ & 3 & 2134 & 6 & $1.8093 \times 10^{5}$ & 5000 \\
\hline & ${ }^{13} \mathrm{CH}_{3}{ }^{13} \mathrm{C}^{14} \mathrm{~N}$ & 4 & 3134 & 12 & $3.7410 \times 10^{5}$ & 5000 \\
\hline 42 & ${ }^{12} \mathrm{C}^{19} \mathrm{~F}_{4}$ & 1 & 29 & 1 & $1.2686 \times 10^{5}$ & 5000. \\
\hline 43 & ${ }^{12} \mathrm{C}_{4} \mathrm{H}_{2}$ & 1 & 2211 & 1 & $9.8215 \times 10^{3}$ & 5000 \\
\hline \multirow[t]{6}{*}{44} & $\mathrm{H}^{12} \mathrm{C}_{3}{ }^{14} \mathrm{~N}$ & 1 & 12224 & 6 & $2.4711 \times 10^{4}$ & 5000 \\
\hline & $\mathrm{H}^{12} \mathrm{C}_{3}{ }^{15} \mathrm{~N}$ & 2 & 12225 & 12 & $1.7040 \times 10^{4}$ & 5000 \\
\hline & $\mathrm{H}^{12} \mathrm{C}^{12} \mathrm{C}^{13} \mathrm{C}^{14} \mathrm{~N}$ & 3 & 12234 & 12 & $4.9897 \times 10^{4}$ & 5000 \\
\hline & $\mathrm{H}^{12} \mathrm{C}^{13} \mathrm{C}^{12} \mathrm{C}^{14} \mathrm{~N}$ & 4 & 12324 & 12 & $4.9728 \times 10^{4}$ & 5000 \\
\hline & $\mathrm{H}^{13} \mathrm{C}^{12} \mathrm{C}^{12} \mathrm{C}^{14} \mathrm{~N}$ & 5 & 13224 & 4 & $5.1552 \times 10^{4}$ & 5000 \\
\hline & $\mathrm{D}^{12} \mathrm{C}^{12} \mathrm{C}^{12} \mathrm{C}^{14} \mathrm{~N}$ & 6 & 22224 & 9 & $4.5928 \times 10^{4}$ & 5000 \\
\hline \multirow[t]{2}{*}{45} & $\mathrm{H}_{2}$ & 1 & 11 & 1 & 7.6712 & 6000 \\
\hline & HD & 2 & 12 & 6 & $2.9874 \times 10^{1}$ & 6000 \\
\hline \multirow[t]{4}{*}{46} & ${ }^{12} \mathrm{C}^{32} \mathrm{~S}$ & 1 & 22 & 1 & $2.5318 \times 10^{2}$ & 5000 \\
\hline & ${ }^{12} C^{34} S$ & 2 & 24 & 1 & $2.5774 \times 10^{2}$ & 5000 \\
\hline & ${ }^{13} C^{32} S$ & 3 & 32 & 2 & $5.3745 \times 10^{2}$ & 5000 \\
\hline & ${ }^{12} \mathrm{C}^{33} \mathrm{~S}$ & 4 & 23 & 4 & $1.0229 \times 10^{3}$ & 5000 \\
\hline 47 & ${ }^{32} \mathrm{~S}^{16} \mathrm{O}_{3}$ & 1 & 26 & 1 & $7.7833 \times 10^{3}$ & 3500 \\
\hline \multirow[t]{2}{*}{48} & ${ }^{14} \mathrm{~N}^{12} \mathrm{C}^{12} \mathrm{C}^{14} \mathrm{~N}$ & 1 & 4224 & 1 & $1.5585 \times 10^{4}$ & 5000 \\
\hline & ${ }^{15} \mathrm{~N}^{12} \mathrm{C}^{12} \mathrm{C}^{15} \mathrm{~N}$ & 2 & 5225 & 1 & $7.3662 \times 10^{3}$ & 5000 \\
\hline \multirow[t]{2}{*}{49} & ${ }^{12} \mathrm{C}^{16} \mathrm{O}^{35} \mathrm{Cl}_{2}$ & 1 & 2655 & 1 & $1.4800 \times 10^{6}$ & 5000 \\
\hline & ${ }^{12} \mathrm{C}^{16} \mathrm{O}^{35} \mathrm{Cl}^{37} \mathrm{Cl}$ & 2 & 2657 & 16 & $3.0435 \times 10^{6}$ & 5000 \\
\hline \multirow[t]{3}{*}{50} & ${ }^{32} \mathrm{~S}^{16} \mathrm{O}$ & 1 & 26 & 1 & $8.4288 \times 10^{2}$ & 3500 \\
\hline & ${ }^{34} \mathrm{~S}^{16} \mathrm{O}$ & 2 & 46 & 1 & $8.5973 \times 10^{2}$ & 3500 \\
\hline & ${ }^{32} \mathrm{~S}^{18} \mathrm{O}$ & 3 & 28 & 1 & $9.1052 \times 10^{2}$ & 3500 \\
\hline 51 & ${ }^{12} \mathrm{CH}_{3}{ }^{19} \mathrm{~F}$ & 1 & 219 & 2 & $1.4707 \times 10^{4}$ & 5000 \\
\hline \multirow[t]{5}{*}{52} & ${ }^{74} \mathrm{GeH}_{4}$ & 1 & 7411 & 1 & $1.6341 \times 10^{3}$ & 5000 \\
\hline & ${ }^{72} \mathrm{GeH}_{4}$ & 2 & 7211 & 1 & $1.6340 \times 10^{3}$ & 5000 \\
\hline & ${ }^{70} \mathrm{GeH}_{4}$ & 3 & 7011 & 1 & $1.6340 \times 10^{3}$ & 5000 \\
\hline & ${ }^{73} \mathrm{GeH}_{4}$ & 4 & 7311 & 10 & $1.6341 \times 10^{4}$ & 5000 \\
\hline & ${ }^{76} \mathrm{GeH}_{4}$ & 5 & 7611 & 1 & $1.6341 \times 10^{3}$ & 5000 \\
\hline \multirow[t]{4}{*}{53} & ${ }^{32} \mathrm{~S}^{12} \mathrm{C}^{32} \mathrm{~S}$ & 1 & 222 & 1 & $1.7187 \times 10^{3}$ & 5000 \\
\hline & ${ }^{32} S^{12} C^{34} S$ & 2 & 224 & 1 & $2.7975 \times 10^{3}$ & 5000 \\
\hline & ${ }^{32} \mathrm{~S}^{12} \mathrm{C}^{33} \mathrm{~S}$ & 3 & 223 & 4 & $1.1009 \times 10^{4}$ & 5000 \\
\hline & ${ }^{32} \mathrm{~S}^{13} \mathrm{C}^{32} \mathrm{~S}$ & 4 & 232 & 2 & $3.5614 \times 10^{3}$ & 5000 \\
\hline \multirow[t]{2}{*}{54} & ${ }^{12} \mathrm{CH}_{3}{ }^{127} \mathrm{I}$ & 1 & 217 & 6 & $1.6427 \times 10^{5}$ & 5000 \\
\hline & ${ }^{13} \mathrm{CH}_{3}{ }^{127} \mathrm{I}$ & 2 & 317 & 12 & $3.4936 \times 10^{5}$ & 5000 \\
\hline
\end{tabular}




\begin{tabular}{rllrlll}
\hline 55 & ${ }^{14} \mathrm{~N}^{19} \mathrm{~F}_{3}$ & 1 & 49 & 3 & $3.4773 \times 10^{5}$ & 5000 \\
\hline 56 & ${ }^{12} \mathrm{C}_{3} \mathrm{H}_{4}$ & 1 & 1221 & 2 & $7.4879 \times 10^{4}$ & 5000 \\
\hline 57 & ${ }^{12} \mathrm{CH}_{3}$ & 1 & 2111 & 1 & $6.6865 \times 10^{2}$ & 5000 \\
\hline
\end{tabular}

